\title{
Bank liquidity, interbank markets, and monetary policy
}

\author{
Xavier Freixas $\quad$ Antoine Martin David Skeie*
}

February 2010

A major lesson of the recent financial crisis is that the interbank lending market is crucial for banks facing large uncertainty regarding their liquidity needs. This paper studies the efficiency of the interbank lending market in allocating funds. We consider two different types of liquidity shocks leading to different implications for optimal policy by the central bank. We show that, when confronted with a distributional liquidity-shock crisis that causes a large disparity in the liquidity held among banks, the central bank should lower the interbank rate. This view implies that the traditional tenet prescribing the separation between prudential regulation and monetary policy should be abandoned. In addition, we show that, during an aggregate liquidity crisis, central banks should manage the aggregate volume of liquidity. Two different instruments, interest rates and liquidity injection, are therefore required to cope with the two different types of liquidity shocks. Finally, we show that failure to cut interest rates during a crisis erodes financial stability by increasing the risk of bank runs.

Keywords: bank liquidity, interbank markets, central bank policy, financial fragility, bank runs

JEL classification: G21, E43, E44, E52, E58

*Freixas is at Universitat Pompeu Fabra. Martin and Skeie are at the Federal Reserve Bank of New York. Author e-mails are xavier.freixas@upf.edu, antoine.martin@ny.frb.org, and david.skeie@ny.frb.org. Part of this research was done while Antoine Martin was visiting the University of Bern, the University of Lausanne, and the Banque de France. We thank Franklin Allen, Jordi Gali, Ricardo Lagos, Thomas Sargent, Joel Shapiro, Iman van Lelyveld, and seminar participants at Universite of Paris X Nanterre, Deutsche Bundesbank, Bank of England, European Central Bank, University of Malaga, Universitat Pompeu Fabra, the Fourth Tinbergen Institute conference (2009), the Financial Stability Conference at Tilburg University, the conference of Swiss Economists Abroad (Zurich 2008), the Federal Reserve Bank of New York's Central Bank Liquidity Tools conference, and the Western Finance Association meetings (2009) for helpful comments and conversations. The views expressed in this paper are those of the authors and do not necessarily reflect the views of the Federal Reserve Bank of New York or the Federal Reserve System. 


\section{Bank liquidity, interbank markets, and monetary policy}

February 2010

A major lesson of the recent financial crisis is that the interbank lending market is crucial for banks facing large uncertainty regarding their liquidity needs. This paper studies the efficiency of the interbank lending market in allocating funds. We consider two different types of liquidity shocks leading to different implications for optimal policy by the central bank. We show that, when confronted with a distributional liquidity-shock crisis that causes a large disparity in the liquidity held among banks, the central bank should lower the interbank rate. This view implies that the traditional tenet prescribing the separation between prudential regulation and monetary policy should be abandoned. In addition, we show that, during an aggregate liquidity crisis, central banks should manage the aggregate volume of liquidity. Two different instruments, interest rates and liquidity injection, are therefore required to cope with the two different types of liquidity shocks. Finally, we show that failure to cut interest rates during a crisis erodes financial stability by increasing the risk of bank runs.

Keywords: bank liquidity, interbank markets, central bank policy, financial fragility, bank runs

JEL classification: G21, E43, E44, E52, E58 


\section{Introduction}

The appropriate response of a central bank's interest rate policy to banking crises is the subject of a continuing and important debate. A standard view is that monetary policy should play a role only if a financial disruption directly affects inflation or the real economy; that is, monetary policy should not be used to alleviate financial distress per se. Additionally, several studies on interlinkages between monetary policy and financialstability policy recommend the complete separation of the two, citing evidence of higher and more volatile inflation rates in countries where the central bank is in charge of banking stability. $^{1}$

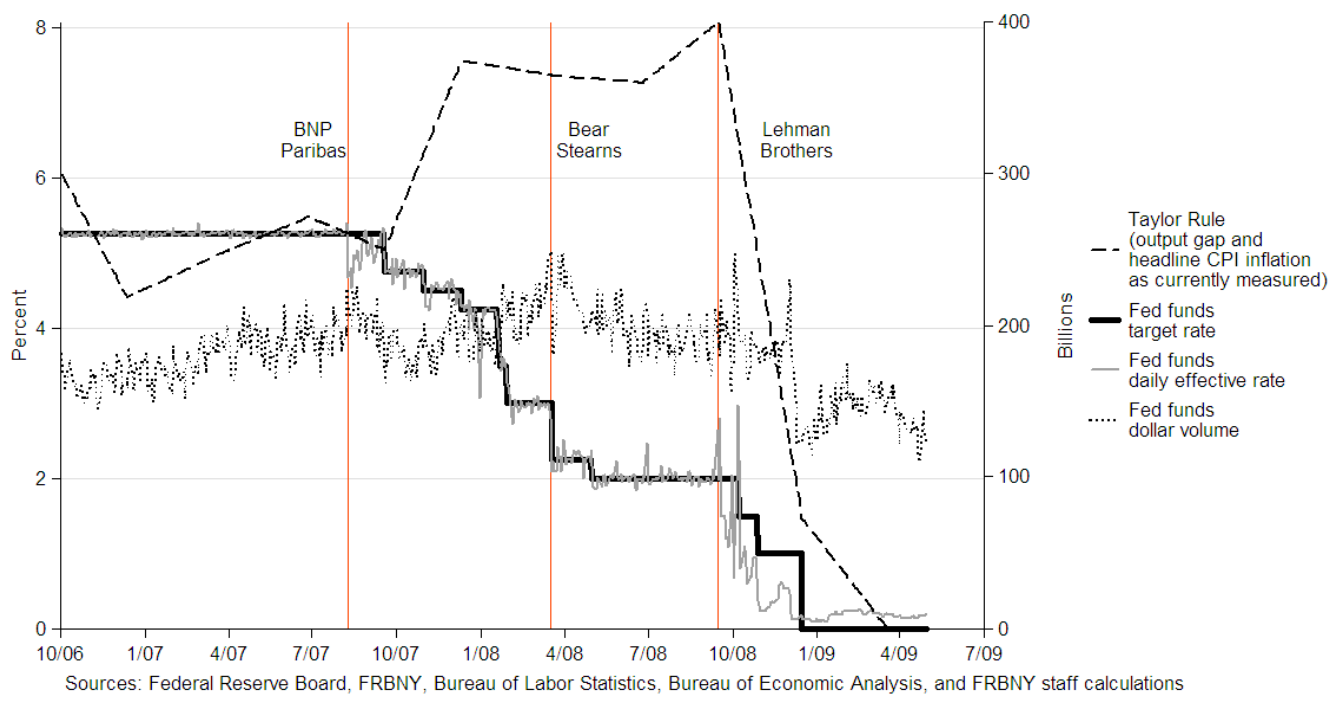

Figure 1: The Taylor Rule and the fed funds rate

This view of monetary policy is challenged by observations that, during a banking crisis, interbank interest rates often appear to be a key instrument used by central banks

\footnotetext{
${ }^{1}$ See Goodhart and Shoenmaker (1995) and Di Giorgio and Di Noia (1999).
} 
for limiting threats to the banking system and interbank markets. During the recent crisis, which began in August 2007, interest rate setting in both the U.S. and the E.U. appeared to be geared heavily toward alleviating stress in the banking system and in the interbank market in particular. Figure 1 shows that the Federal Reserve sharply cut the fed funds target rate well below the rate prescribed by the Taylor Rule (as measured by the current output gap and headline CPI inflation), which is a primary benchmark for interest rate policy based on concerns of output and inflation. Interest rate policy has been used similarly in previous financial disruptions, as Goodfriend (2002) indicates: "Consider the fact that the Fed cut interest rates sharply in response to two of the most serious financial crises in recent years: the October 1987 stock market break and the turmoil following the Russian default in 1998." The practice of reducing interbank rates during financial turmoil also challenges the long-debated view originated by Bagehot (1873) that central banks should provide liquidity to banks at high-penalty interest rates (see Martin 2009, for example).

We develop a model of the interbank market and show that the central bank's interest rate policy can directly improve liquidity conditions in the interbank lending market during a financial crisis. Consistent with central bank practice, the optimal policy in our model consists of reducing the interbank rate during a crisis. This view implies that the conventionally supported separation between prudential regulation and monetary policy should be abandoned.

Intuition for our results can be gained by understanding the role of the interbank market. The main purpose of this market is to redistribute the fixed amount of reserves that is held within the banking system. In our model, banks may face uncertainty regarding their need for liquid assets, which we associate with reserves. The interbank market allows banks faced with distributional shocks to redistribute liquid assets among them- 
selves. The interest rate will therefore play a key role in amplifying or reducing the losses of banks enduring liquidity shocks.

Our model is well suited to think about the tremendous uncertainty and disparity in liquidity needs among banks during the crisis. Many banks were subject to explicit and implicit guarantees to provide liquidity funding for asset-backed commercial paper (ABCP) conduits, structured investment vehicles (SIVs), and other credit lines. These banks had potential liquidity risks of needing to pay billions of dollars on a same-day notice. European banks were especially in need of dollar funds. Many of those banks had very large funding needs for dollar asset-backed securities, and they had little access to U.S. domestic dollar deposits. In contrast, other banks received large inflows of funds from financial investors who were fleeing AAA-rated securities, financial commercial paper, and money market funds in a flight to liquidity. Many U.S. banks also had access to domestic retail and commercial dollar deposits.

A key theoretical innovation of our model captures the variation of liquidity needs that was observed among banks during the crisis. We introduce two different states of the world regarding the uncertainty of the distribution of liquidity required by banks. We associate a state of high uncertainty with a crisis and a state of low uncertainty with normal times. We also permit the interbank market rate to be state dependent. According to our model, the central bank should lower the interbank interest rate during the crisis state to improve the redistribution of liquidity among banks; we also predict that interbank lending increases as banks redistribute liquidity. Despite widespread claims that interbank markets froze, the volume of fed funds lending actually increased during the period that the Federal Reserve cut the fed funds rate, as shown in Figure 1.

A novel result of our model is that there are multiple Pareto-ranked equilibria associated with different pairs of interbank market rates for normal and crisis times. The 
multiplicity of equilibria arises because the demand for and supply of funds in the interbank market are inelastic. This inelasticity is a key feature of our model and corresponds to the fundamentally inelastic nature of banks' short-term liquidity needs. We show that the role for the central bank is to determine a unique equilibrium interbank rate and to select the equilibrium that produces the optimal allocation.

Figure 1 shows the fed funds target rate, which is the announced rate that the Federal Reserve uses as its instrument for interest rate policy. The figure also shows the effective fed funds rate, which is the daily average of interest rates on uncollateralized overnight loans among banks. The figure illustrates that as the Federal Reserve lowered its target rate during the financial turmoil, the effective rate was roughly centered around the target most of the time. Despite brief periods when the effective rate deviated from the target, the Federal Reserve was generally able to determine the average overnight fed funds rate. We do not study counterparty risk, which is important for examining credit spreads in longer term interbank lending. However, credit risk plays a small role relative to liquidity risk in the overnight market, which is the primary market for banks to handle their short term liquidity needs.

The interbank interest rate plays two roles in our model. From an ex-ante perspective, the expected rate is the return from holding liquidity, and it influences the banks' portfolio decision for holding short-term liquid assets and long-term illiquid assets. Ex post, the rate determines the terms at which banks can borrow liquid assets in response to distributional shocks, so that a trade-off is present between the two roles. The optimal allocation can be achieved only with state-contingent interbank rates. The rate must be low in crisis times to achieve the efficient redistribution of liquid assets. Yet in order to make low interest rates during a crisis compatible with the higher return on banks' long-term assets, during normal times interbank interest rates must be higher than the return on long-term assets 
to induce banks to hold optimal liquidity ex ante. As the conventional separation of prudential regulation and monetary policy implies that interest rates are set independently of prudential considerations, our result is a strong criticism of such separation.

Our framework yields several additional results. First, when aggregate liquidity shocks are considered, we show that the central bank should accommodate the shocks by injecting or withdrawing liquidity. Interest rates and liquidity injections should be used to address two different types of liquidity shocks: Interest rate management allows for coping with efficient liquidity reallocation in the interbank market, while injections of liquidity allow for tackling aggregate liquidity shocks. Hence, when interbank markets are modeled as part of an optimal institutional arrangement, the central bank should respond to different types of shocks with different tools. Second, we show that the failure to implement a contingent interest rate policy, which will occur if the separation between monetary policy and prudential regulation prevails, will undermine financial stability by increasing the probability of bank runs.

In their seminal study, Bhattacharya and Gale (1987) examine banks with idiosyncratic liquidity shocks from a mechanism design perspective. In their model, when liquidity shocks are not observable, the interbank market is not efficient and the second-best allocation involves setting a limit on the size of individual loan contracts among banks. More recent work by Freixas and Holthausen (2005), Freixas and Jorge (2008), and Heider, Hoerova, and Holthausen (2008) examines interbank markets that are not part of an optimal arrangement. Allen, Carletti, and Gale (2008) make an advancement by developing a framework in which interbank markets are efficient. The central bank responds to idiosyncratic and aggregate shocks by buying and selling particular quantities of assets, using its balance sheet to achieve the efficient allocation. 
Building on Bhattacharya and Gale (1987) and Allen, Carletti, and Gale (2008), the modeling innovation in our paper is to introduce a richer state space of multiple distributional liquidity-shock states. We show that this additional state-space dimension allows the central bank to address liquidity shocks with an additional tool, namely a dynamic interest rate policy, which is the standard instrument of central bank policy in practice. We show that with state-contingent interbank rates, the central bank can achieve the full-information efficient allocation.

Goodfriend and King (1988) argue that central bank policy should respond to aggregate, but not idiosyncratic, liquidity shocks, because interbank markets are efficient and can distribute liquidity optimally. We show how central bank policy needs to respond to shocks in the distribution of liquidity in order for interbank markets to operate efficiently. The results of our paper also relate to those of Diamond and Rajan (2008), who show that interbank rates should be low during a crisis and high in normal times. Diamond and Rajan (2008) examine the limits of central bank influence over bank interest rates based on a Ricardian equivalence argument, whereas we find a new mechanism by which the central bank can adjust interest rates based on the inelasticity of banks' short-term supply of and demand for liquidity. Our paper also relates to Bolton, Santos and Scheinkman (2008), who consider the trade-off faced by financial intermediaries between holding liquidity versus acquiring liquidity supplied by a market after shocks occur. Efficiency depends on the timing of central bank intervention in Bolton et al. (2008), whereas in our paper the level of interest rates is the focus. Acharya and Yorulmazer (2008) consider interbank markets with imperfect competition. Gorton and Huang (2006) study interbank liquidity historically provided by banking coalitions through clearinghouses. Ashcraft, McAndrews, and Skeie (2008) examine a model of the interbank market with credit and participation frictions that can explain their empirical findings of reserves hoarding by banks and extreme 
interbank rate volatility.

Section 2 presents the model of distributional shocks. Section 3 gives the market results and central bank interest rate policy. Section 4 analyzes aggregate shocks, and Section 5 examines financial fragility. Available liquidity is endogenized in Section 6. Section 7 concludes.

\section{Model}

The model has three dates, denoted by $t=0,1,2$, and a continuum of competitive banks, each with a unit continuum of consumers. Ex-ante identical consumers are endowed with one unit of good at date 0 and learn their private type at date 1 . With a probability $\bar{\lambda} \in$ $(0,1)$, a consumer is "impatient" and needs to consume at date 1 . With complementary probability $1-\bar{\lambda}$, a consumer is "patient" and needs to consume at date 2 . Throughout the paper, we disregard sunspot-triggered bank runs. At date 0, consumers deposit their unit good in their bank for a deposit contract that pays an amount when withdrawn at either date 1 or 2 .

There are two possible technologies. The short-term liquid technology, also called liquid assets, allows for storing goods at date 0 or date 1 for a return of one in the following period. The long-term investment technology, also called long-term assets, allows for investing goods at date 0 for a return of $r>1$ at date 2 . Investment is illiquid and cannot be liquidated at date $1 .^{2}$

At date 1, each bank faces stochastic withdrawals that are bank-specific. There is no aggregate withdrawal risk for the banking system as a whole; on average, each bank has $\bar{\lambda}$ withdrawals at date $1 .^{3}$ We model distributional liquidity shocks by allowing the size

\footnotetext{
${ }^{2}$ We extend the model to allow for liquidation at date 1 in Section 6 .

${ }^{3}$ We study a model with distributional and aggregate shocks in Section 4.
} 
of the bank-specific liquidity shocks to vary with the distributional liquidity-shock state variable $i \in \mathcal{I} \equiv\{0,1\}$, where

$$
i=\left\{\begin{array}{lll}
1 & \text { with prob } \rho & \text { ("crisis state") } \\
0 & \text { with prob } 1-\rho & \text { ("normal-times state") }
\end{array}\right.
$$

and $\rho \in[0,1]$ is the probability of the crisis liquidity-shock state $i=1$. We assume that state $i$ is observable but not verifiable, which means that contracts cannot be written contingent on state $i$. Banks are ex-ante identical at date 0. At date 1, each bank learns its private type $j \in \mathcal{J} \equiv\{h, l\}$, where

$$
j=\left\{\begin{array}{lll}
h & \text { with prob } \frac{1}{2} \quad(\text { "high type") } \\
l \quad \text { with prob } \frac{1}{2} \quad(\text { "low type"). }
\end{array}\right.
$$

In aggregate, half of banks are type $h$ and half are type $l$. Banks of type $j \in \mathcal{J}$ have a fraction of impatient depositors at date 1 equal to

$$
\lambda^{i j}=\left\{\begin{array}{lll}
\bar{\lambda}+i \varepsilon & \text { for } j=h & \text { ("high withdrawals") } \\
\bar{\lambda}-i \varepsilon & \text { for } j=l & \text { ("low withdrawals") }
\end{array}\right.
$$

where $i \in \mathcal{I}$ and $\varepsilon>0$ is the size of the bank-specific withdrawal shock. We assume that $0<\lambda^{i l} \leq \lambda^{i h}<1$ for $i \in \mathcal{I}$.

To summarize, under the liquidity-shock state $i=1$, a crisis occurs and there is a large distributional shift in liquidity among banks. Banks of type $j=h$ have relatively high liquidity withdrawals at date 1 and banks of type $j=l$ have relatively low liquidity withdrawals. Under the liquidity-shock state $i=0$, there is no crisis, and the size of the distributional shift in liquidity is zero. All banks have constant withdrawals of $\bar{\lambda}$ at date 1. Under either state, at date 2 the remaining depositors withdraw. Banks of type $j \in \mathcal{J}$ have a fraction of depositor withdrawals equal to $1-\lambda^{i j}, i \in \mathcal{I}$.

A depositor receives consumption of either $c_{1}$ for withdrawal at date 1 or $c_{2}^{i j}$, an equal share of the remaining goods at the depositor's bank $j$, for withdrawal at date 2 . Depositor 
utility is

$$
U=\left\{\begin{array}{lll}
u\left(c_{1}\right) & \text { with prob } \bar{\lambda} & \text { ("impatient depositors") } \\
u\left(c_{2}^{i j}\right) & \text { with prob } 1-\bar{\lambda} & \text { ("patient depositors") },
\end{array}\right.
$$

where $u$ is increasing and concave. We define $c_{2}^{0} \equiv c_{2}^{0 j}$ for all $j \in \mathcal{J}$, since consumption for impatient depositors of each bank type is equal during normal-times state $i=0$. A depositor's expected utility is

$$
E[U]=\bar{\lambda} u\left(c_{1}\right)+(1-\rho)(1-\bar{\lambda}) u\left(c_{2}^{0}\right)+\rho\left[\frac{1}{2}\left(1-\lambda^{1 h}\right) u\left(c_{2}^{1 h}\right)+\frac{1}{2}\left(1-\lambda^{1 l}\right) u\left(c_{2}^{1 l}\right)\right] .
$$

Banks maximize profits. Because of competition, they must maximize the expected utility of their depositors. Banks invest $\alpha \in[0,1]$ in long-term assets and store $1-\alpha$ in liquid assets. At date 1, depositors and banks learn their private type. Bank $j$ borrows $f^{i j} \in \mathbb{R}$ liquid assets on the interbank market (the notation $f$ represents the federal funds market and $f^{i j}<0$ represents a loan made in the interbank market) and impatient depositors withdraw $c_{1}$. At date 2 , bank $j$ repays the amount $f^{i j} \iota^{i}$ for its interbank loan and the bank's remaining depositors withdraw, where $\iota^{i}$ is the interbank interest rate. If $\iota^{0} \neq \iota^{1}$, the interest rate is state contingent, whereas if $\iota^{0}=\iota^{1}$, the interest rate is not state contingent. Since banks are able to store liquid assets for a return of one between dates 1 and 2 , banks never lend for a return of less than one, so $\iota^{i} \geq 1$ for all $i \in \mathcal{I}$. A timeline is shown in Figure 2. 


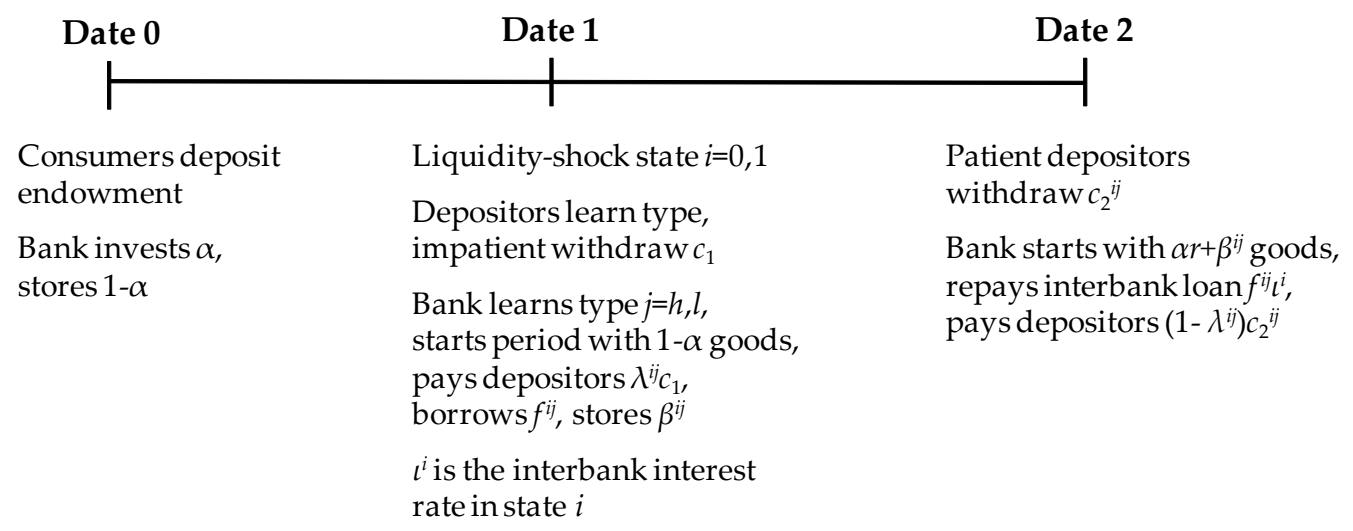

Figure 2: Timeline

The bank budget constraints for bank $j$ for dates 1 and 2 are

$$
\begin{aligned}
\lambda^{i j} c_{1} & =1-\alpha-\beta^{i j}+f^{i j} \quad \text { for } i \in \mathcal{I}, j \in \mathcal{J} \\
\left(1-\lambda^{i j}\right) c_{2}^{i j} & =\alpha r+\beta^{i j}-f^{i j} \iota^{i} \quad \text { for } i \in \mathcal{I}, j \in \mathcal{J},
\end{aligned}
$$

respectively, where $\beta^{i j} \in[0,1-\alpha]$ is the amount of liquid assets that banks of type $j$ store between dates 1 and 2 . We assume that the coefficient of relative risk aversion for $u(c)$ is greater than one, which implies that banks provide risk-decreasing liquidity insurance. We also assume that banks lend liquid assets when indifferent between lending and storing. We only consider parameters such that there are no bank defaults in equilibrium. ${ }^{4}$ As such, we assume that incentive compatibility holds:

$$
c_{2}^{i j} \geq c_{1} \quad \text { for all } i \in \mathcal{I}, j \in \mathcal{J}
$$

which rules out bank runs based on very large bank liquidity shocks.

The bank optimizes over $\alpha, c_{1},\left\{c_{2}^{i j}, \beta^{i j}, f^{i j}\right\}_{i \in \mathcal{I}, j \in \mathcal{J}}$ to maximize its depositors' expected utility. From the date 1 budget constraint (3), we can solve for the quantity of

\footnotetext{
${ }^{4}$ Bank defaults and insolvencies that cause bank runs are considered in Section 5.
} 
interbank borrowing by bank $j$ as

$$
f^{i j}\left(\alpha, c_{1}, \beta^{i j}\right)=\lambda^{i j} c_{1}-(1-\alpha)+\beta^{i j} \quad \text { for } i \in \mathcal{I}, j \in \mathcal{J}
$$

Substituting this expression for $f^{i j}$ into the date 2 budget constraint (4) and rearranging gives consumption by patient depositors as

$$
c_{2}^{i j}\left(\alpha, c_{1}, \beta^{i j}\right)=\frac{\alpha r+\beta^{i j}-\left[\lambda^{i j} c_{1}-(1-\alpha)+\beta^{i j}\right] \iota^{i}}{\left(1-\lambda^{i j}\right)} .
$$

The bank's optimization can be written as

$$
\begin{array}{rl}
\max _{\alpha \in[0,1] ; c_{1},\left\{\beta^{i j}\right\}_{i \in \mathcal{I}, j \in \mathcal{J} \geq 0}} & E[U] \\
\text { s.t. } & \beta^{i j} \leq 1-\alpha \text { for } i \in \mathcal{I}, j \in \mathcal{J} \\
& c_{2}^{i j}\left(\alpha, c_{1}, \beta^{i j}\right)=\frac{\alpha r+\beta^{i j}-\left[\lambda^{i j} c_{1}-(1-\alpha)+\beta^{i j}\right] \iota^{i}}{\left(1-\lambda^{i j}\right)} \text { for } i \in \mathcal{I}, j \in \mathcal{J},
\end{array}
$$

where constraint (8) gives the maximum amount of liquid assets that can be stored between dates 1 and 2 .

The clearing condition for the interbank market is

$$
f^{i h}=-f^{i l} \quad \text { for } i \in \mathcal{I} \text {. }
$$

An equilibrium consists of contingent interbank market interest rates and an allocation such that banks maximize profits, consumers make their withdrawal decisions to maximize their expected utility, and the interbank market clears.

\section{Results and interest rate policy}

In this section, we derive the optimal allocation and characterize equilibrium allocations. We start by showing that the optimal allocation is independent of the liquidity-shock 
state $i \in \mathcal{I}$ and bank types $j \in \mathcal{J}$. Next, we derive the Euler and no-arbitrage conditions. After that, we study the special cases in which a "crisis never occurs" when $\rho=0$ and in which a "crisis always occurs" when $\rho=1$. This allows us to build intuition for the general case where $\rho \in[0,1]$.

\subsection{First best allocation}

To find the full-information first best allocation, we consider a planner who can observe consumer types. The planner can ignore the liquidity-shock state $i$, bank type $j$, and bank liquidity withdrawal shocks $\lambda^{i j}$. The planner maximizes the expected utility of depositors subject to feasibility constraints:

$$
\begin{aligned}
\max _{\alpha \in[0,1] ; c_{1}, \beta \geq 0} & \bar{\lambda} u\left(c_{1}\right)+(1-\bar{\lambda}) u\left(c_{2}\right) \\
\text { s.t. } & \bar{\lambda} c_{1} \leq 1-\alpha-\beta \\
& (1-\bar{\lambda}) c_{2} \leq \alpha r+1-\alpha+\beta-\bar{\lambda} c_{1} \\
& \beta \leq 1-\alpha .
\end{aligned}
$$

The constraints are the physical quantities of goods available for consumption at date 1 and 2, and available storage between dates 1 and 2, respectively. The first-order conditions and binding constraints give the well-known first best allocations, denoted with asterisks, as implicitly defined by

$$
\begin{aligned}
u^{\prime}\left(c_{1}^{*}\right) & =r u^{\prime}\left(c_{2}^{*}\right) \\
\bar{\lambda} c_{1}^{*} & =1-\alpha^{*} \\
(1-\bar{\lambda}) c_{2}^{*} & =\alpha^{*} r \\
\beta^{*} & =0 .
\end{aligned}
$$


Equation (11) shows that the ratio of marginal utilities between dates 1 and 2 is equal to the marginal return on investment $r$.

\subsection{First-order conditions}

Next, we consider the optimization problem of a bank of type $j$ given by equations (7) (9) in order to find the Euler and no-arbitrage pricing equations.

Lemma 1. First-order conditions with respect to $c_{1}$ and $\alpha$ are, respectively,

$$
\begin{aligned}
u^{\prime}\left(c_{1}\right) & =E\left[\frac{\lambda^{i j}}{\bar{\lambda}} \iota^{i} u^{\prime}\left(c_{2}^{i j}\right)\right] \\
E\left[\iota^{i} u^{\prime}\left(c_{2}^{i j}\right)\right] & =r E\left[u^{\prime}\left(c_{2}^{i j}\right)\right],
\end{aligned}
$$

Banks do not store liquid assets from date 1 to date 2:

$$
\beta^{i j}=0 \text { for all } i \in \mathcal{I}, j \in \mathcal{J} \text {. }
$$

Proof. The Lagrange multiplier for constraint $(8)$ is $\theta_{\beta}^{i j}$. The first-order condition with respect to $\beta^{i j}$ is

$$
\begin{aligned}
\frac{1}{2} \rho u^{\prime}\left(c_{2}^{1 j}\right)\left(1-\iota^{1}\right) & \leq \theta_{\beta}^{1 j} \quad \text { for } j \in \mathcal{J} \quad\left(=\text { if } \beta^{1 j}>0\right) \\
(1-\rho) u^{\prime}\left(c_{2}^{0}\right)\left(1-\iota^{0}\right) & \leq \theta_{\beta}^{0 j} \quad \text { for } j \in \mathcal{J} \quad\left(=\text { if } \beta^{0 j}>0\right) .
\end{aligned}
$$

We first will show that $\theta_{\beta}^{i j}=0$ for all $i \in \mathcal{I}, j \in \mathcal{J}$. Suppose not, that $\theta_{\beta}^{\widehat{i j}}>0$ for some $\widehat{i} \in \mathcal{I}, \widehat{j} \in \mathcal{J}$. This implies that equation (18) or (19) corresponding to $\hat{i}, \widehat{j}$ does not bind (since $\iota^{i} \geq 1$ ), which implies that $\beta^{\widehat{i j}}=0$. Hence, equation (8) does not bind (since clearly $\alpha<1$, otherwise $c_{1}=0$ ); thus, $\theta_{\beta}^{\widehat{\imath} j}=0$ by complementary slackness, a contradiction. Taking the first order conditions of equations (7) - (9) with respect to $c_{1}$ and $\alpha$, and substituting for $\theta_{\beta}^{i j}=0$ for $i \in \mathcal{I}, j \in \mathcal{J}$ gives equations (15) and (16), respectively. 
Next, suppose $\beta^{i j}>0$ for some $i \in \mathcal{I}, j \in \mathcal{J}$. Substituting from the interbank borrowing demand equation (5) into the market clearing condition (10) and simplifying shows that total bank storage at date 1 in state $\iota=0$ and $\iota=1$ must be equal:

$$
\begin{aligned}
& \beta^{0 h}+\beta^{0 l}=2\left(1-\alpha-\lambda c_{1}\right) \\
& \beta^{1 h}+\beta^{1 l}=2\left(1-\alpha-\lambda c_{1}\right) .
\end{aligned}
$$

Since $\beta^{i j} \geq 0, \beta^{0 j}>0$ for some $j \in \mathcal{J}$ if and only if $\beta^{1 j^{\prime}}>0$ for some $j^{\prime} \in \mathcal{J}$. Conditions (18) and (19) imply that $\iota^{0}=\iota^{1}=1$, which implies by condition (16) that $r=1$, a contradiction. Hence, $\beta^{i j}=0$ for all $i \in \mathcal{I}, j \in \mathcal{J}$.

Equation (15) is the Euler equation and determines the investment level $\alpha$ given $\iota^{i}$ for $i \in \mathcal{I}$. Equation (16), which corresponds to the first-order condition with respect to $\alpha$, is the no-arbitrage pricing condition for the rate $\iota^{i}$, which states that the expected marginal utility-weighted returns on storage and investment must be equal at date $t=0$. The return on investment is $r$. The return on storage is the rate $\iota^{i}$ at which liquid assets can be lent at date 1 , since banks can store liquid assets at date 0 , lend them at date 1 , and will receive $\iota^{i}$ at date 2 . At the interest rates $\iota^{1}$ and $\iota^{0}$, banks are indifferent to holding liquid assets and long-term assets at date 0 according to the no-arbitrage condition.

The interbank market-clearing condition (10), together with the interbank market demand equation (5), determines $c_{1}^{j}(\alpha)$ and $f^{i j}(\alpha)$ as functions of $\alpha$ :

$$
\begin{aligned}
c_{1}(\alpha)= & \frac{1-\alpha}{\bar{\lambda}} \\
f^{i j}(\alpha)= & (1-\alpha)\left(\frac{\lambda^{i j}}{\bar{\lambda}}-1\right) \quad \text { for } i \in \mathcal{I}, j \in \mathcal{J} \\
= & \left\{\begin{array}{r}
i \varepsilon c_{1} \quad \text { for } i \in \mathcal{I}, j=h \\
-i \varepsilon c_{1} \quad \text { for } i \in \mathcal{I}, j=l .
\end{array}\right.
\end{aligned}
$$

Since no liquid assets are stored between dates 1 and 2 for state $i=0,1$, patient depositors' consumption $c_{2}^{0}$ in state $i=0$ equals the average of patient depositors' consumption 
$c_{2}^{i j}$ in state $i=1$ and equals total investment returns $\alpha r$ divided by the mass of impatient depositors $1-\bar{\lambda}$ :

$$
\begin{aligned}
c_{2}^{0}(\alpha) & =\frac{\left(1-\lambda^{1 h}\right) c_{2}^{1 h}+\left(1-\lambda^{1 l}\right) c_{2}^{1 l}}{1-\bar{\lambda}} \\
& =\frac{\alpha r}{1-\bar{\lambda}} .
\end{aligned}
$$

The choice of $\alpha$ is given in the next subsections, where the full equilibrium results are derived.

\subsection{Single liquidity-shock state: $\rho \in\{0,1\}$}

We start by finding solutions to the special cases of $\rho \in\{0,1\}$ in which there is certainty about the single state of the world $i$ at date 1 . These are particularly interesting benchmarks. In the case of $\rho=0$, the state $i=0$ is always realized. This case corresponds to the standard framework of Diamond and Dybvig (1983) and can be interpreted as a crisis never occurring. In the case of $\rho=1$, the state $i=1$ is always realized. This corresponds to the case studied by Bhattacharya and Gale (1987) and can be interpreted as a crisis always occurring. These boundary cases will then help to solve the general model $\rho \in[0,1]$.

With only a single possible state of the world at date 1 , it is easy to show that the interbank rate must equal the return on long-term assets. First-order conditions (15) and (16) can be written more explicitly as

$$
\begin{aligned}
u^{\prime}\left(c_{1}\right)= & \rho\left[\frac{\lambda^{1 h}}{2 \bar{\lambda}} u^{\prime}\left(c_{2}^{1 h}\right)+\frac{\lambda^{1 l}}{2 \bar{\lambda}} u^{\prime}\left(c_{2}^{1 l}\right)\right] \iota^{1}+(1-\rho) u^{\prime}\left(c_{2}^{0}\right) \iota^{0} \\
& \rho\left[\frac{1}{2} u^{\prime}\left(c_{2}^{1 h}\right)+\frac{1}{2} u^{\prime}\left(c_{2}^{1 l}\right)\right] \iota^{1}+(1-\rho) u^{\prime}\left(c_{2}^{0}\right) \iota^{0} \\
= & \rho\left[\frac{1}{2} u^{\prime}\left(c_{2}^{1 h}\right)+\frac{1}{2} u^{\prime}\left(c_{2}^{1 l}\right)\right] r+(1-\rho) u^{\prime}\left(c_{2}^{0}\right) r .
\end{aligned}
$$


As is intuitive, for $\rho=0$, the value of $\iota^{1}$ is indeterminate, and for $\rho=1$, the value of $\iota^{0}$ is indeterminate. In either case, there is an equilibrium with a unique allocation $c_{1}, c_{2}^{i j}$, and $\alpha$. The indeterminate variable is of no consequence for the allocation. The allocation is determined by the two first-order equations, in the two unknowns $\alpha$ and $\iota^{0}$ (for $\rho=0$ ) or $\iota^{1}$ (for $\left.\rho=1\right)$. Equation (24) shows that the interbank lending rate equals the return on long-term assets: $\iota^{0}=r($ for $\rho=0)$ or $\iota^{1}=r($ for $\rho=1)$. With a single state of the world, the interbank lending rate must equal the return on long-term assets.

For $\rho=0$, the crisis state never occurs. There is no need for banks to borrow on the interbank market. The banks' budget constraints imply that in equilibrium no interbank lending occurs, $f^{0 j}=0$ for $j \in \mathcal{J}$. However, the interbank lending rate $\iota^{0}$ still plays the role of clearing markets: It is the lending rate at which each bank's excess demand is zero, which requires that the returns on liquidity and investment are equal. The result is $\iota^{0}=r$, which is an important market price that ensures banks hold optimal liquidity. Our result - that the banks' portfolio decision is affected by a market price at which there is no trading - is similar to the effect of prices with no trading in equilibrium in standard portfolio theory and asset pricing with a representative agent. The Euler equation (23) is equivalent to equation (11) for the planner. Banks choose the optimal $\alpha^{*}$ and provide the first best allocation $c_{1}^{*}$ and $c_{2}^{*}$.

Proposition 1. For $\rho=0$, the equilibrium is characterized by $\iota^{0}=r$ and has a unique first best allocation $c_{1}^{*}, c_{2}^{*}, \alpha^{*}$.

Proof. For $\rho=0$, equation (24) implies $\iota^{0}=r$. Equation (23) simplifies to $u^{\prime}\left(c_{1}\right)=$ $u^{\prime}\left(c_{2}^{0}\right) r$, and the bank's budget constraints bind and simplify to $c_{1}=\frac{1-\alpha}{\bar{\lambda}}, c_{2}^{0}=\frac{\alpha r}{1-\bar{\lambda}}$. These results are equivalent to the planner's results in equations (11) through (13), implying there is a unique equilibrium, where $c_{1}=c_{1}^{*}, c_{2}^{0}=c_{2}^{*}$, and $\alpha=\alpha^{*}$. 
To interpret these results, note that banks provide liquidity at date 1 to impatient depositors by paying $c_{1}^{*}>1$. This can be accomplished only by paying $c_{2}^{*}<r$ on withdrawals to patient depositors at date 2. The key for the bank being able to provide liquidity insurance to impatient depositors is that the bank can pay an implicit date 1 to date 2 intertemporal return on deposits of only $\frac{c_{2}^{*}}{c_{1}^{*}}$, which is less than the interbank market intertemporal rate $\iota^{0}$, since $\frac{c_{2}^{*}}{c_{1}^{*}}<\iota^{0}=r$. This contract is optimal because the ratio of intertemporal marginal utility equals the marginal return on long-term assets, $\frac{u^{\prime}\left(c_{2}^{*}\right)}{u^{\prime}\left(c_{1}^{*}\right)}=r$

We now turn to the symmetric case of $\rho=1$, where the crisis state $i=1$ always occurs. We show that, in this case, the optimal allocation cannot be obtained, even though interbank lending provides redistribution of liquidity. Nevertheless, because the interbank rate is high, $\iota^{1}=r$, patient depositors face inefficient consumption risk, and the liquidity provided to impatient depositors is reduced. The banks' borrowing demand from equation (21) shows that $f^{1 h}=\varepsilon c_{1}$ and $f^{1 l}=-\varepsilon c_{1}$.

First, consider the outcome at date 1 holding fixed $\alpha=\alpha^{*}$. With $\iota^{1}=r$, patient depositors do not have optimal consumption since $c_{2}^{1 h}\left(\alpha^{*}\right)<c_{2}^{*}<c_{2}^{1 l}\left(\alpha^{*}\right)$. A bank of type $h$ has to borrow at date 1 at the rate $\iota^{1}=r$, higher than the optimal rate of $\frac{c_{2}^{*}}{c_{1}^{*}}$.

Second, consider the determination of $\alpha$. Banks must compensate patient depositors for the risk they face. They can do so by increasing their expected consumption. Hence, in equilibrium, investment is $\alpha>\alpha^{*}$ and impatient depositors see a decease of their consumption. The results are illustrated in Figure 3. The difference of consumption $c_{2}^{0}$ for equilibrium $\alpha$ compared to $c_{2}^{*}\left(\alpha^{*}\right), c_{2}^{1 h}\left(\alpha^{*}\right)$, and $c_{2}^{1 l}(\alpha)$ for a fixed $\alpha=\alpha^{*}$ is demonstrated by the arrows in Figure 3. The result is $c_{1}<c_{1}^{*}, c_{2}^{0}>c_{2}^{*}, c_{2}^{1 h}>c_{2}^{1 h}\left(\alpha^{*}\right)$, and $c_{2}^{1 l}>c_{2}^{1 l}\left(\alpha^{*}\right)$. For any $\varepsilon>0$ shock, banks do not provide the optimal allocation. 


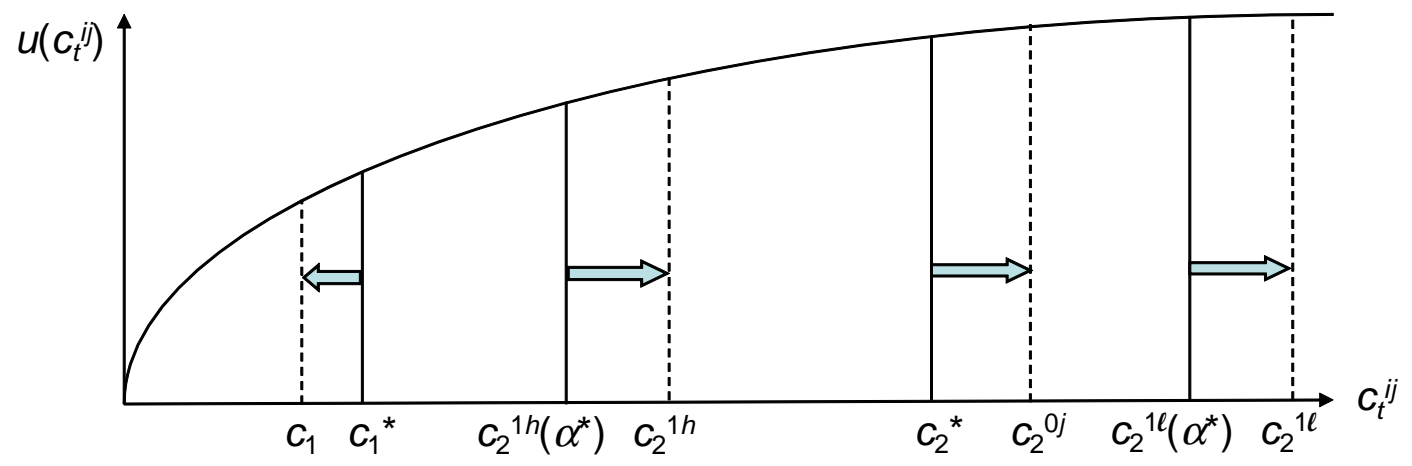

Figure 3: First best allocation and equilibrium allocation for $\rho=1$

Proposition 2. For $\rho=1$, there exists an equilibrium characterized by $\iota^{1}=r$ that has a unique suboptimal allocation

$$
\begin{aligned}
c_{1} & <c_{1}^{*} \\
c_{2}^{1 h} & <c_{2}^{*}<c_{2}^{1 l} \\
\alpha & >\alpha^{*} .
\end{aligned}
$$

Proof. For $\rho=1$, equation (24) implies $\iota^{1}=r$. By equation (6), $c_{2}^{1 l}>c_{2}^{1 h}$. From the bank's budget constraints and market clearing,

$$
\frac{1-\bar{\lambda}-\varepsilon}{2(1-\bar{\lambda})} c_{2}^{1 h}+\frac{1-\bar{\lambda}+\varepsilon}{2(1-\bar{\lambda})} c_{2}^{1 l}=\frac{\alpha r}{1-\bar{\lambda}}=c_{2}^{0},
$$

which implies $\frac{1}{2} c_{2}^{1 h}+\frac{1}{2} c_{2}^{1 l}<c_{2}^{0}$, since $c_{2}^{1 l}>c_{2}^{1 h}$. Because $u(\cdot)$ is concave, $\frac{1}{2} u^{\prime}\left(c_{2}^{1 h}\right)+\frac{1}{2} u^{\prime}\left(c_{2}^{1 l}\right)>$ $u^{\prime}\left(c_{2}^{0}\right)$. Further, $\frac{\lambda^{1 h}}{2 \bar{\lambda}} u^{\prime}\left(c_{2}^{1 h}\right)+\frac{\lambda^{1 l}}{2 \bar{\lambda}} u^{\prime}\left(c_{2}^{1 l}\right)>u^{\prime}\left(c_{2}^{0}\right)$ since $\lambda^{1 h}>\lambda^{1 l}, \frac{\lambda^{1 h}}{2 \bar{\lambda}}+\frac{\lambda^{1 l}}{2 \bar{\lambda}}=1$ and $c_{2}^{1 h}<c_{2}^{1 l}$. Thus,

$$
\begin{aligned}
u^{\prime}\left(c_{1}\left(\alpha^{*}\right)\right) & =r u^{\prime}\left(c_{2}^{0}\left(\alpha^{*}\right)\right) \\
& <r\left[\frac{\lambda^{1 h}}{2 \bar{\lambda}} u^{\prime}\left(c_{2}^{1 h}\left(\alpha^{*}\right)\right)+\frac{\lambda^{1 l}}{2 \bar{\lambda}} u^{\prime}\left(c_{2}^{1 l}\left(\alpha^{*}\right)\right)\right] .
\end{aligned}
$$

Since $u^{\prime}\left(c_{1}(\alpha)\right)$ is increasing in $\alpha$ and $u^{\prime}\left(c_{2}^{1 j}(\alpha)\right)$ for $j \in \mathcal{J}$ is decreasing in $\alpha$, the Euler equation implies that, in equilibrium, $\alpha>\alpha^{*}$. Hence, $c_{1}=\frac{1-\alpha}{\bar{\lambda}}<c_{1}^{*}, c_{2}^{1 l}>c_{2}^{0}=\frac{\alpha r}{1-\bar{\lambda}}>c_{2}^{*}$ and $c_{2}^{1 h}<c_{2}^{*}$ 
Notice that, for $\rho=1$, the difference between our approach and that of Bhattacharya and Gale (1987) is that in our framework the market cannot impose any restriction on the size of the trades. This forces the interbank market to equal $r$ and creates an inefficiency. The mechanism design approach of Bhattacharya and Gale (1987) yields a second best allocation that achieves higher welfare, but in that case the market cannot be anonymous anymore, as the size of the trade has to be observed and enforced.

\subsection{Multiple liquidity-shock states: $\rho \in[0,1]$}

We now apply our results for the special cases $\rho \in\{0,1\}$ to the general case $\rho \in[0,1]$. It is convenient to define an ex-post equilibrium, which refers to the interest rate that clears the interbank market in state $i$ at date 1 , conditional on a given $\alpha$ and $c_{1}$. For distinction, we use the term ex-ante equilibrium to refer to our equilibrium concept used above from the perspective of date 0 . We first show that the supply and demand in the interbank market are inelastic, which creates an indeterminacy of the ex-post equilibrium interest rate. Next, we show that there is a real indeterminacy of the ex-ante equilibrium. There is a continuum of Pareto-ranked ex-ante equilibria with different values for $c_{1}, c_{2}^{i j}$, and $\alpha$.

We first show the indeterminacy of the ex-post equilibrium interest rate. In state $i=1$, the amount of liquid assets that bank type $l$ supplies in the interbank market is

$$
-f^{1 l}\left(\iota^{1}\right)= \begin{cases}\varepsilon c_{1} & \text { for } \iota^{1} \geq 1 \\ 0 & \text { for } \iota^{1}<1 .\end{cases}
$$

The liquid bank has an inelastic supply of liquid assets above a rate of one because its alternative to lending is storage, which gives a return of one. Bank type $h$ has a demand 
for liquid assets of

$$
\begin{aligned}
& 0 \text { for } \iota^{1}>1+\frac{(1-\bar{\lambda})\left(c_{2}^{0}-c_{1}\right)}{\varepsilon c_{1}} \\
& f^{1 h}\left(\iota^{1}\right)=\left\{\varepsilon c_{1} \quad \text { for } \iota^{1} \in\left[1,1+\frac{(1-\bar{\lambda})\left(c_{2}^{0}-c_{1}\right)}{\varepsilon c_{1}}\right]\right. \\
& \infty \text { for } \iota^{1}<1 \text {. }
\end{aligned}
$$

The maximum rate $\iota^{1}$ at which the illiquid bank type $j$ can borrow, such that the incentive constraint $c_{2}^{1 h} \geq c_{1}$ holds and patient depositors do not withdraw at date 1 , is $1+$ $\frac{(1-\bar{\lambda})\left(c_{2}^{0}-c_{1}\right)}{\varepsilon c_{1}}$. The illiquid bank has an inelastic demand for liquid assets below the rate $\iota^{1}$ because its alternative to borrowing is to default on withdrawals to impatient depositors at date 1 . The banks' supply and demand curves for date 1 are illustrated in Figure 4. In state $i=0$, each bank has an inelastic net demand for liquid assets of

$$
f^{0 j}\left(\iota^{0}\right)= \begin{cases}0 & \text { for } \iota^{0} \geq 1 \\ \infty & \text { for } \iota^{0}<1 .\end{cases}
$$

At a rate of $\iota^{0}>1$, banks do not have any liquid assets they can lend in the market. All such assets are needed to cover the withdrawals of impatient depositors. At a rate of $\iota^{0}<1$, a bank could store any amount of liquid assets borrowed for a return of one.

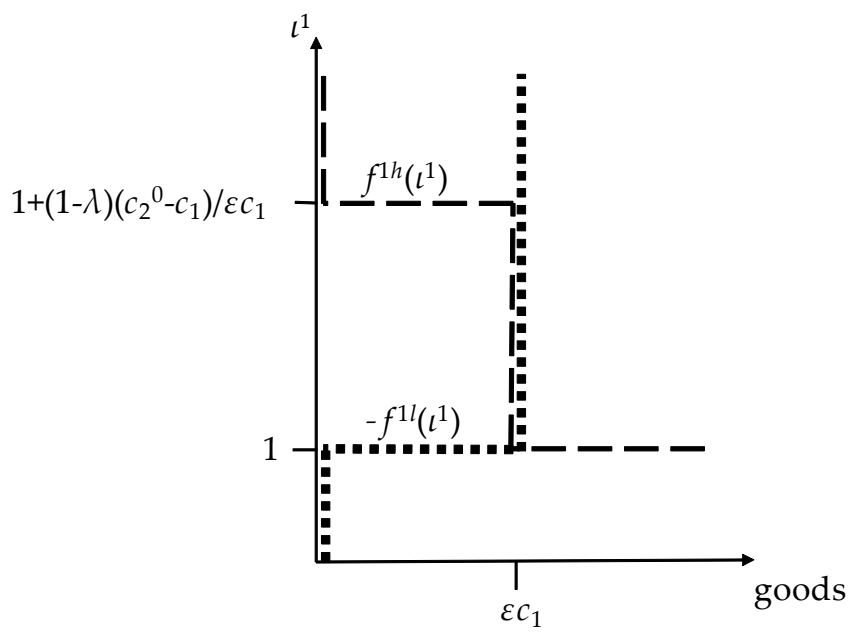

Figure 4: Interbank market in state $i=1$ 
Lemma 2. The ex-post equilibrium rate $\iota^{i}$ in state $i$, for $i \in \mathcal{I}$, is indeterminate:

$$
\begin{aligned}
& \iota^{0} \geq 1 \\
& \iota^{1} \in\left[1,1+\frac{(1-\bar{\lambda})\left(c_{2}^{0}-c_{1}\right)}{\varepsilon c_{1}}\right] .
\end{aligned}
$$

Proof. Substituting for $f^{0 j}\left(\iota^{0}\right)$ from (27), for $j \in \mathcal{J}$, into market-clearing condition (10) and solving gives the condition for the equilibrium rate $\iota^{0}$. Substituting for $f^{1 l}\left(\iota^{1}\right)$ and $f^{1 h}\left(\iota^{l}\right)$ from (25) and (26) into market-clearing condition (10) and solving gives the corresponding condition for the equilibrium rate $\iota^{1}$.

This result highlights a key feature of our model: The supply and demand of short-term liquidity are fundamentally inelastic. By the nature of short-term financing, distributional liquidity shocks imply that liquidity held in excess of immediate needs is of low fundamental value to the bank that holds it, while demand for liquidity for immediate needs is of high fundamental value to the bank that requires it to prevent default. The interest rate $\iota^{i}$ determines how gains from trade are shared ex-post among banks. Low rates benefit illiquid banks and their claimants, and decrease impatient depositors' consumption risk, which increases ex-ante expected utility for all depositors.

Next, we show that there exists a continuum of Pareto-ranked ex-ante equilibria. Finding an equilibrium amounts to solving the two first-order conditions, equations (15) and (16), in three unknowns, $\alpha, \iota^{1}$, and $\iota^{0}$. This is a key difference with respect to the benchmark cases of $\rho=0,1$. For each of these cases, there is only one state that occurs with positive probability, and the corresponding state interest rate is the only ex-post equilibrium rate that is relevant. Hence, there are two relevant variables, $\alpha$ and $\iota^{i}$, where $i$ is the relevant state, that are uniquely determined by the two first-order conditions.

In the general two-states model, a bank faces a distribution of probabilities over two interest rates. A continuum of pairs $\left(\iota^{1}, \iota^{0}\right)$ supports an ex-ante equilibrium. This result 
is novel in showing that, when there are two distributional liquidity states $i$ at date 1, there exists a continuum of ex-ante equilibria. ${ }^{5}$ Allen and Gale (2004) also show that a continuum of interbank rates can support an ex-post sunspot equilibrium. However, because they consider a model with a single state, the only rate that supports an ex-ante equilibrium is $r$, similar to our benchmark case of $\rho=1$.

If the interbank rate is not state contingent, $\iota^{1}=\iota^{0}=r$ is the unique equilibrium, as is clear from equation (24). The allocation resembles a weighted average of the cases $\rho \in\{0,1\}$ and is suboptimal, showing an important drawback of the separation between prudential regulation and monetary policy. In the case where $\iota^{1}=\iota^{0}=r$, equation (23) implies that $\alpha(\rho), c_{2}^{0}(\rho), c_{2}^{1 h}(\rho)$, and $c_{2}^{1 l}(\rho)$ are implicit functions of $\rho$. The cases of $\rho=0$ and $\rho=1$ provide bounds for the general case of $\rho \in[0,1]$. Equilibrium consumption $c_{1}(\rho)$ and $c_{2}^{i j}(\rho)$ for $i \in \mathcal{I}, j \in \mathcal{J}$, written as functions of $\rho$, are displayed in Figure 5 . This figure shows that $c_{1}(\rho)$ is decreasing in $\rho$ while $c_{2}^{i j}(\rho)$ is increasing in $\rho$ :

$$
\begin{aligned}
& c_{2}^{i j}(0) \leq c_{2}^{i j}(\rho) \leq c_{2}^{i j}(1) \quad \text { for } \rho \in[0,1], i \in \mathcal{I}, j \in \mathcal{J} \\
& c_{1}(1) \leq c_{1}(\rho) \leq c_{1}(0) \quad \text { for } \rho \in[0,1] .
\end{aligned}
$$

In addition,

$$
\begin{array}{rlrl}
c_{2}^{0}(\rho=0) & =c_{2}^{*} & & \text { for } j \in \mathcal{J} \\
c_{1}(\rho=0) & =c_{1}^{*} & \\
c_{2}^{1 j}(\rho=0) & =c_{2}^{1 j}\left(\alpha=\alpha^{*}\right) & & \text { for } j \in \mathcal{J} .
\end{array}
$$

With interbank rates equal to $r$ in all states, patient depositors face too much risk. To compensate them for this risk, their expected consumption must be increased to the detriment of impatient depositors.

\footnotetext{
${ }^{5}$ The results from this section generalize in a straightforward way to the case of $N$ states, as shown in the Appendix.
} 


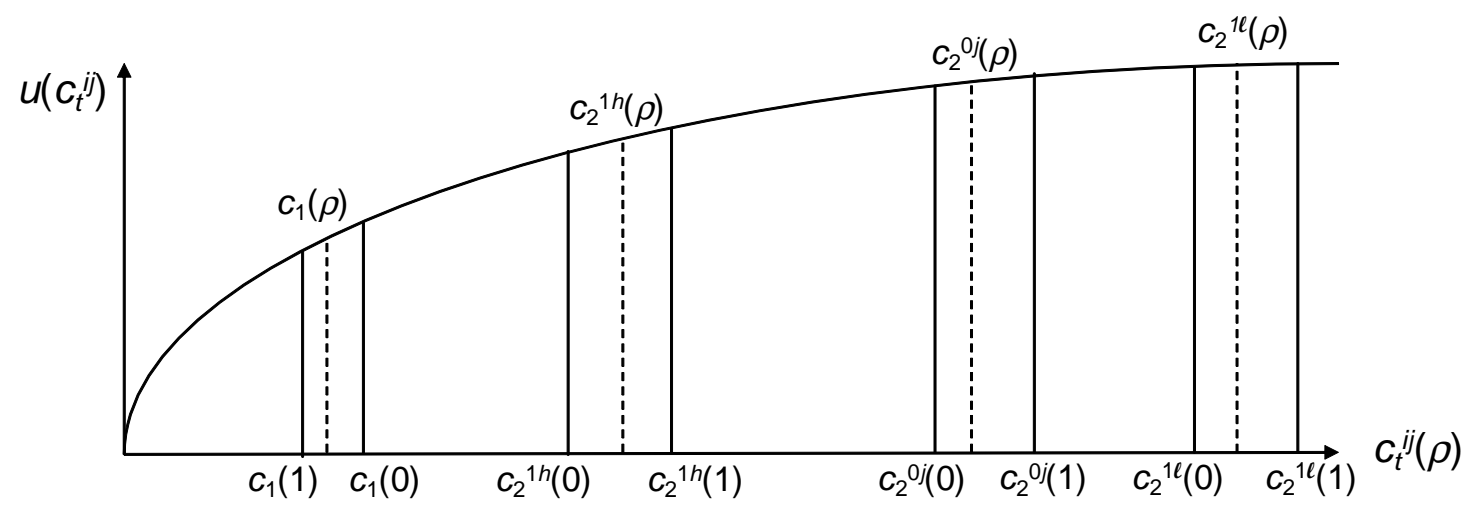

Figure 5: Equilibrium allocation for $\rho \in[0,1]$

Finally, we show that there exists a first best ex-ante equilibrium with state contingent interest rates for $\rho<1$. The interest rate must equal the optimal return on bank deposits during a crisis:

$$
\iota^{1}=\iota^{1^{*}} \equiv \frac{c_{2}^{*}}{c_{1}^{*}}<r
$$

To show this, first we substitute for $\iota^{1}, \lambda^{i j}, c_{1}$, and $\beta^{i j}$ from equations (28), (1), (20), and (17) into equation (6) and simplify, which for $i=1$ and $j=h, l$ gives

$$
c_{2}^{1 h}=c_{2}^{1 l}=\frac{\alpha r}{1-\bar{\lambda}}
$$

This shows that, with $\iota^{1}$ equal to the optimal intertemporal return on deposits between dates 1 and 2, there is optimal risk-sharing of the goods that are available at date 2 . This implies that the interbank market rate has to be low for patient depositors to face no risk. Substituting for $\iota^{1}, c_{2}^{1 j}$, and $c_{2}^{0}$ from equations (28), (29), and (22), respectively, into equation (24) and rearranging gives the interest rate in state $i=0$ :

$$
\iota^{0}=r+\frac{\rho\left(r-\frac{c_{2}^{0}}{c_{1}}\right)}{1-\rho}
$$

and further substituting for these variables into equation (23) and rearranging gives $u^{\prime}\left(c_{1}\right)=r^{\prime} u^{\prime}\left(c_{2}^{0}\right)$. This is the planner's condition and implies $\alpha=\alpha^{*}, c_{1}=c_{1}^{*}$, and $c_{2}^{0}=c_{2}^{*}$, a first best allocation. 
Substituting these equilibrium values into equation (30) and simplifying shows that

$$
\iota^{0}=\iota^{0^{*}} \equiv r+\frac{\rho\left(r-\frac{c_{2}^{*}}{c_{1}^{*}}\right)}{1-\rho}>r .
$$

The market rate $\iota^{0}$ must be greater than $r$ during the no-shock state, in order for the expected rate to equal $r$, such that banks are indifferent to holding liquid assets and investing at date 0 . Equation (16) implies, then, that the expected market rate is $E\left[\iota^{i}\right]=r$.

Figure 6 illustrates the difference between the first best equilibrium (with $\iota^{1^{*}}, \iota^{0^{*}}$ ) and the suboptimal equilibrium (with $\iota^{1}=\iota^{0}=r$ ). Arrows indicate the change in consumption between the suboptimal and the first best equilibria.

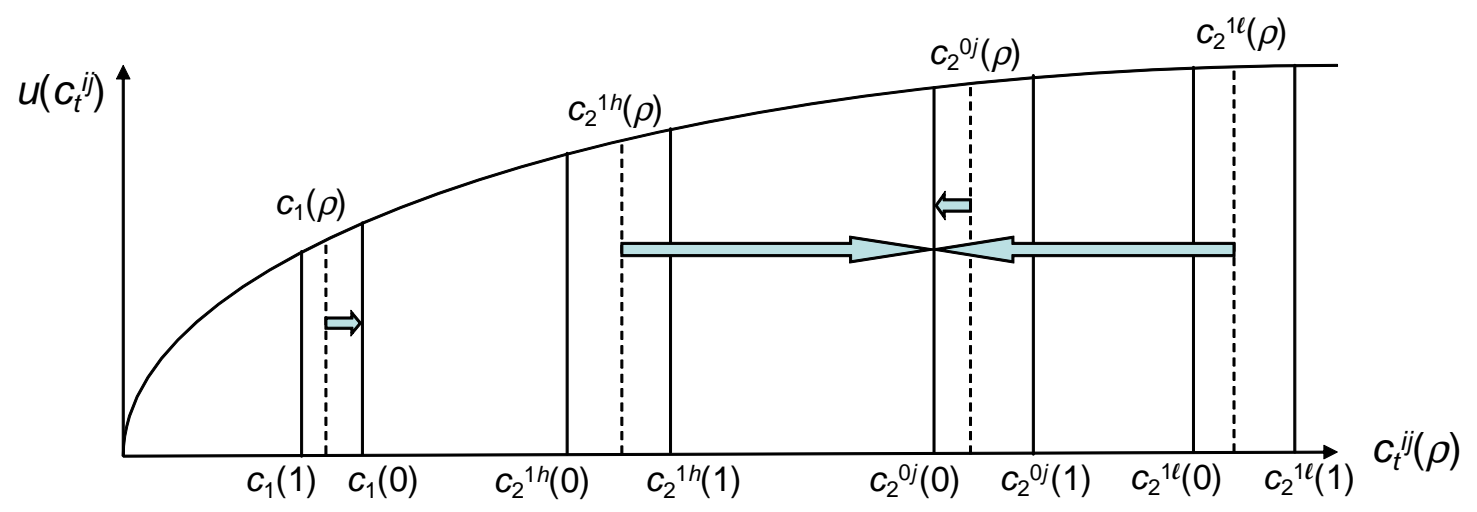

Figure 6: Difference between equilibrium allocation and first best allocation for $\rho \in[0,1]$

Proposition 3. For $\rho \in(0,1)$, there exists a continuum of ex-ante equilibria with different Pareto-ranked allocations. In particular, there exists a suboptimal ex-ante equilibrium with

$$
\begin{aligned}
\iota^{1} & =\iota^{0}=r \\
\alpha & >\alpha^{*} \\
c_{1} & <c_{1}^{*}<c_{2}^{*}<c_{2}^{0} \\
c_{2}^{1 h} & <c_{2}^{*}<c_{2}^{1 l},
\end{aligned}
$$


corresponding to a noncontingent monetary policy and a first best ex-ante equilibrium with

$$
\begin{aligned}
\iota^{1} & =\frac{c_{2}^{*}}{c_{1}^{*}}<r \\
\iota^{0} & =\iota^{0^{*}}>r \\
\alpha & =\alpha^{*} \\
c_{1} & =c_{1}^{*} \\
c_{2}^{i j} & =c_{2}^{*} \quad \text { for } i \in \mathcal{I}, j \in \mathcal{J} .
\end{aligned}
$$

\subsection{Central bank interest rate policy}

The result of multiple Pareto-ranked equilibria and a need for a state-contingent interest rate in our model suggest a role for an institution that can select the best equilibrium. Since equilibria can be distinguished by the interest rate in the interbank market, a central bank is the natural candidate for this role. A central bank can select the optimal equilibrium and intervene by targeting the optimal market interest rate. We think of the interest rate $\iota^{i}$ at which banks lend in the interbank market as the unsecured interest rate that many central banks target for monetary policy. In the U.S., the Federal Reserve targets the overnight interest rate, also known as the federal funds rate.

We extend the model by adding a central bank that can offer to borrow an amount $\Delta>0$ below $\iota^{i *}$ and lend an amount $\Delta>0$ above $\iota^{i *}$ on the interbank market in order to target the interbank rate equal to $\iota^{i *}$. The central bank's objective is to maximize the depositor's expected utility equation (2), subject to the bank's optimization equations (7) through (9), by submitting the following demand and supply functions, respectively, for 
the interbank market:

$$
\begin{gathered}
f^{i D}\left(\iota^{i}\right)=\left\{\begin{array}{l}
0 \quad \text { for } \iota^{i} \geq \iota^{i *}, \quad i \in \mathcal{I} \\
\Delta \quad \text { for } \iota^{i}<\iota^{i *} \quad i \in \mathcal{I}
\end{array}\right. \\
f^{i S}\left(\iota^{i}\right)=\left\{\begin{array}{r}
-\Delta \text { for } \iota^{i}>\iota^{i *}, \quad i \in \mathcal{I} \\
0 \text { for } \iota^{i} \leq \iota^{i *}, \quad i \in \mathcal{I},
\end{array}\right.
\end{gathered}
$$

for any $\Delta>0$. The goods-clearing condition for the interbank market (10) is replaced by

$$
f^{i h}\left(\iota^{i}\right)+f^{i D}\left(\iota^{i}\right)=-\left[f^{i l}\left(\iota^{i}\right)+f^{i S}\left(\iota^{i}\right)\right] \quad \text { for } i \in \mathcal{I} .
$$

Substituting for the supply and demand functions, the market-clearing condition (34) can be written as

$$
i \varepsilon c_{1}+\mathbf{1}_{\iota^{i}<\iota^{i *}} \Delta=i \varepsilon c_{1}+\mathbf{1}_{\iota^{i}>\iota^{i *}} \Delta \quad \text { for } i \in \mathcal{I}
$$

which, for any $\Delta>0$, holds for the unique state $i$ ex-post equilibrium rate $\iota^{i}=\iota^{i *}$, for $i \in$ $\mathcal{I}$. The ex-post equilibrium rate in state $i=1$ is shown in Figure 7 . The figure illustrates how the central bank shifts the market supply and demand curves such that there is a unique equilibrium at $\iota^{1 *}$. At $\iota^{i *}$, the equilibrium quantity that clears the market according to condition (34) is $i \varepsilon c_{1}$. The quantity $\Delta$, with which the central bank intervenes out of equilibrium, is irrelevant. The state-conditional equilibrium rate is uniquely determined as $\iota^{i *}$ and the ex-ante equilibrium is uniquely determined as $\left(\alpha^{*}, \iota^{0 *}, \iota^{1 *}\right)$, for any $\Delta>0$. 


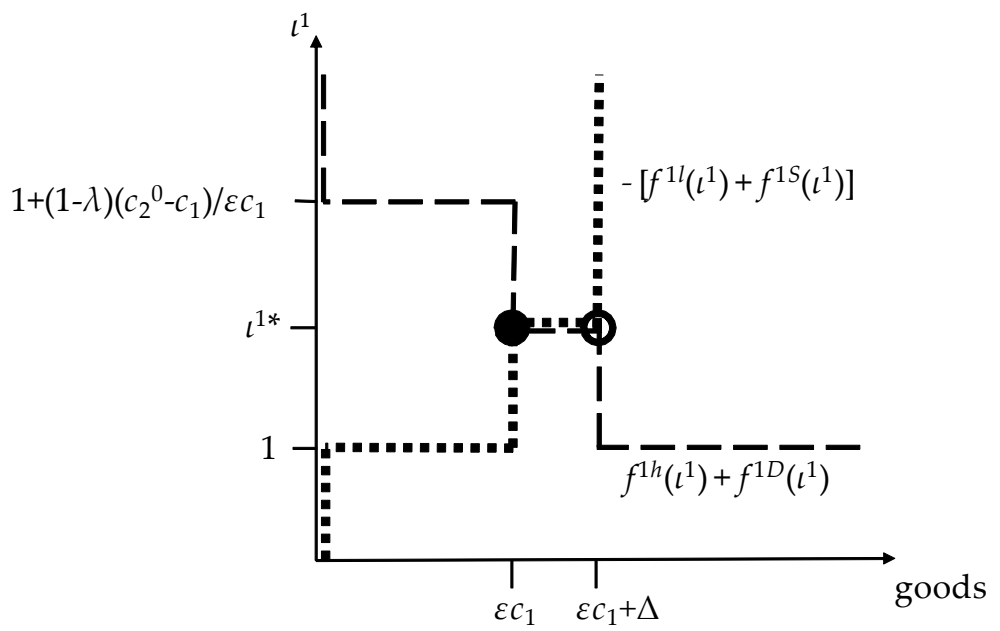

Figure 7: Interbank market in state $i=1$ with optimal central

bank interest rate policy

Proposition 4. Under optimal central bank interest rate policy, the central bank sets $\iota^{1}=\iota^{1 *}<r$ and $\iota^{0}=\iota^{0 *}>r$. There exists a unique ex-ante equilibrium, which has a first best allocation $\alpha^{*}, c_{1}^{*}, c_{2}^{*}$.

This proposition provides the main policy result of our model. Several things are worth noting. First, the central bank should respond to pure distributional liquidity shocks, i.e., involving no aggregate-withdrawal liquidity shocks, by lowering the interbank rate. Second, the central bank must keep the interbank rate sufficiently high in normal times to provide banks with incentives to invest enough in liquid assets. Third, the policy rule should be announced in advance so that banks can anticipate the central bank's state-contingent actions.

All of our results hold in a version of our model where bank deposit contracts are expressed in nominal terms and fiat money is borrowed and lent at nominal rates in the interbank market, along the lines of Skeie (2008) and Martin (2006). In the nominal version of the model, the central bank targets the real interbank rate by offering to borrow 
and lend at a nominal rate in fiat central bank reserves rather than goods (see Appendix B in Freixas, Martin, and Skeie (2009)). This type of policy resembles more closely the standard tools used by central banks.

\subsection{Discussion and evidence}

A key feature of our model is the inelasticity of banks' supply and demand for liquidity, which leads to the multiplicity of market clearing interbank rates absent central bank intervention. There are several pieces of evidence suggesting that in practice, banks may have inelastic supply and demand for reserves, and interbank rates may be indeterminate.

Ashcraft, McAndrews and Skeie (2008) give empirical evidence of the inelasticity of supply and demand for bank reserves. They also show theoretical support to explain the inelasticity of supply and demand for bank reserves during the crisis before the intereston-reserves regime was implemented on October 9, 2008. In the absence of bank reserve requirements, the marginal return on bank reserves held overnight must equal either zero or the shadow cost of borrowing reserves from the discount window. The reason is that if a bank has a positive supply of reserves (i.e. a long position), the overnight return on marginal reserves held in reserve accounts at the Federal Reserve is zero. If instead the bank has a negative supply of reserves (i.e. a short position), then the bank has an overdraft with the Federal Reserve. The bank must cover this overdraft by borrowing at the discount window at a cost of the discount rate plus any potential stigma cost of accessing the discount window. Many times throughout the crisis, reserve requirements

were not binding, which would imply that banks effectively had inelastic supply and demand for reserves.

Figure 8 shows the daily intraday high-low range of interest rates at which fed funds lending occurred during the crisis. The effective fed funds rate was typically close to 
the target, which shows that the Federal Reserve could generally determine the average daily rate with the daily open market operations (offering to borrow or lend reserves) that the Federal Reserve scheduled each morning. However, the fed funds market trades all throughout the day. During the afternoon when the Federal Reserve was not intervening in the market, the fed funds rate often traded over the course of a few hours at extremely different rates in a range of several hundred basis points from nearly zero to above the discount rate. This evidence is consistent with banks' having very inelastic supply and demand for short term liquidity.

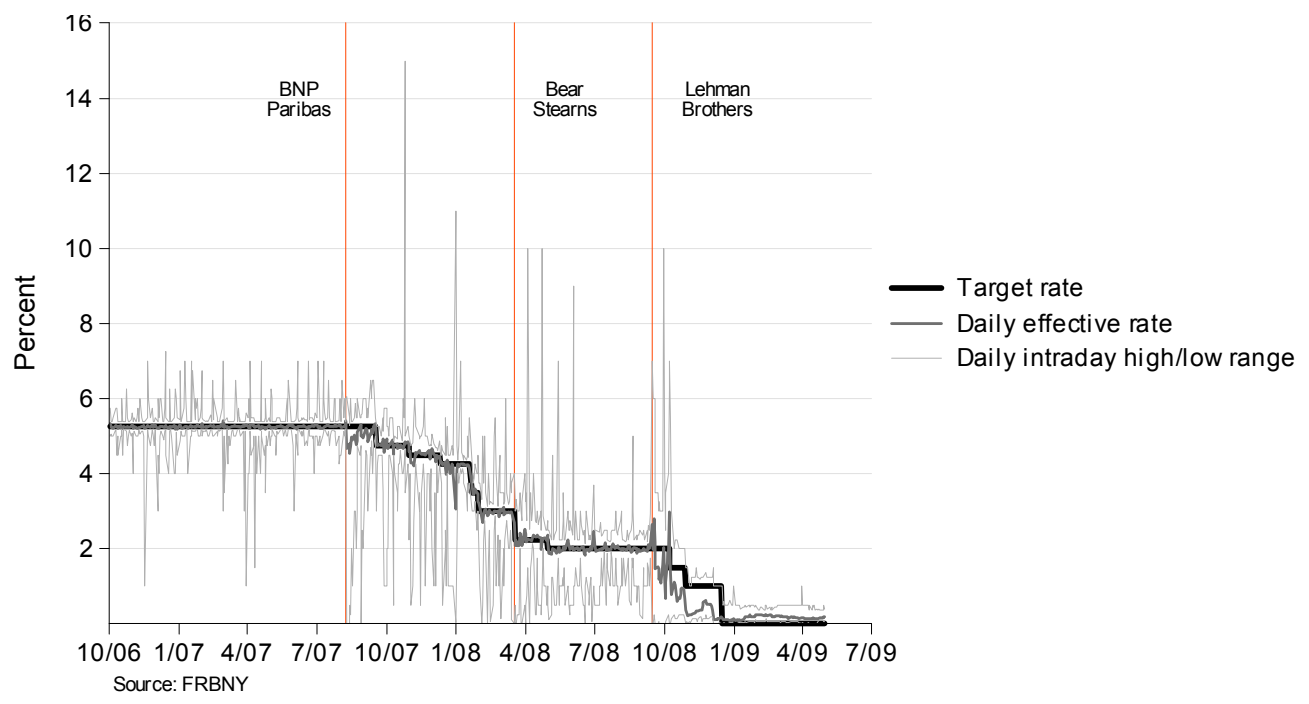

Figure 8: Fed funds rate and intraday range

Further evidence that the interbank market can clear at any of a range of interest rates chosen by the central bank without requiring actual liquidity intervention is suggested by the appearance of "open mouth operations." This term refers to the broadly recognized ability of many central banks to adjust short-term market rates by announcing their intended rate target, without any trading or lending by the central bank in equilibrium. Guthrie and Wright (2000) describe monetary policy implementation in New Zealand as working through open mouth operations. Open mouth operations have also been used to 
describe how the Federal Reserve changes the level of reserves in the banking system only very slightly to effect interest rate changes after the target change has been announced. Often, the fed funds rate changes in anticipation of the announcement of a change in the target rate in advance of any intervention by the Federal Reserve. In our model, zero trading is required by the central bank in equilibrium, and the amount $\Delta$ of borrowing and lending offered by the central bank approaches zero in the limit.

Other examples of highly inelastic bank supply and demand for reserves comes from countries with low aggregate bank reserves and wide interest rate corridors (or channels). These corridors are methods of monetary policy implementation that have been used in Canada, New Zealand, the ECB, the UK, and other countries. A corridor consists of standing facilities at which banks can lend or borrow reserves at the central bank on a daily basis at the corridor deposit or lending rates, respectively. Whitesell (2006) shows that with a very small amount of reserves in the banking system, banks have very inelastic supply and demand for reserves in the interbank market for reasons similar to the analysis of the fed funds market by Ashcraft, McAndrews and Skeie (2008) as described above. In our model, the central bank supply and demand curves resemble a corridor system of zero width.

In Section 6 below, we examine the robustness of a bank's inelastic demand when a bank has options for liquidation of its assets outside of borrowing on the interbank market. The possibility of liquidation of investment may restrict the set of feasible real interbank rates and may preclude the central bank from selecting the first best equilibrium with interest rate policy. We show that interbank market rates that are larger than the return on liquidation are not feasible. However, even with outside liquidity options, the general principle of the model holds. Inelastic supply and demand for liquidity within a range of interest rates implies that there can be some indeterminacy of market clearing interest 
rates, and the central bank can implement the constrained efficient rates among them.

\section{Aggregate shocks and central bank liquidity injec- tions}

The standard view on aggregate liquidity shocks is that they should be dealt with through open market operations, as advocated by Goodfriend and King (1988), for example. Since our framework provides micro-foundations for the interbank market, and this has consequences for the overall allocation, it is worth revisiting the issue of aggregate liquidity shocks. Despite the apparent complexity, we verify that the central bank should use a liquidity injection policy in the face of aggregate shocks. Thus, the central bank should respond to different kinds of shocks with different policy instruments: liquidity injection to deal with aggregate liquidity shocks and interest rate policy for distributional liquidity shocks.

We extend the model to allow the probability of a depositor being impatient - and, hence, the aggregate fraction of impatient depositors in the economy - to be stochastic. This probability is denoted by $\bar{\lambda}_{a}$, where $a \in \mathcal{A} \equiv\{H, L\}$ is the aggregate-shock state,

$$
a= \begin{cases}H & \text { with prob } \pi \\ L & \text { with prob } 1-\pi,\end{cases}
$$

and $\pi \in[0,1]$. The state $a=H$ denotes a high aggregate-withdrawal liquidity shock, in which a high fraction of depositors are impatient, and state $a=L$ denotes a low aggregate-withdrawal liquidity shock, in which a low fraction of depositors are impatient. We assume that $\bar{\lambda}_{H} \geq \bar{\lambda}_{L}$ and $\pi \bar{\lambda}_{H}+(1-\pi) \bar{\lambda}_{L}=\bar{\lambda}$. Hence, $\bar{\lambda}$ remains the unconditional fraction of impatient depositors. The aggregate-withdrawal state random variable $a$ is 
independent of the distributional-state variable $i{ }^{6}$ We assume that the central bank can tax the endowment of agents at date 0 , store these goods, and return the taxes at date 1 or at date 2. We denote these transfers, which can be conditional on the aggregate shock, $\tau_{0}, \tau_{1 a}, \tau_{2 a}, a \in \mathcal{A}$, respectively.

The depositor's expected utility (2) is replaced by

$$
\begin{aligned}
E[U]= & {\left[\pi \bar{\lambda}_{H}+(1-\pi) \bar{\lambda}_{L}\right] u\left(c_{1}\right) } \\
& +(1-\rho)\left[\pi\left(1-\bar{\lambda}_{H}\right) u\left(c_{2 H}^{0}\right)+(1-\pi)\left(1-\bar{\lambda}_{L}\right) u\left(c_{2 L}^{0}\right)\right] \\
& +\rho \frac{\pi}{2}\left[\left(1-\lambda_{H}^{1 h}\right) u\left(c_{2 H}^{1 h}\right)+\left(1-\lambda_{H}^{1 l}\right) u\left(c_{2 H}^{1 l}\right)\right] \\
& +\rho \frac{1-\pi}{2}\left[\left(1-\lambda_{L}^{1 h}\right) u\left(c_{2 L}^{1 h}\right)+\left(1-\lambda_{L}^{1 l}\right) u\left(c_{2 L}^{1 l}\right)\right],
\end{aligned}
$$

and the bank's budget constraints (3) and (4) are replaced by

$$
\begin{aligned}
\lambda_{a}^{i j} c_{1} & =1-\tau_{0}-\alpha-\beta_{a}^{i j}+f_{a}^{i j}+\tau_{1 a}, \quad \text { for } a \in \mathcal{A}, i \in \mathcal{I}, j \in \mathcal{J} \\
\left(1-\lambda_{a}^{i j}\right) c_{a 2}^{i j} & =\alpha r+\beta_{a}^{i j}-f_{a}^{i j} \iota_{a}^{i}+\tau_{2 a}, \quad \text { for } a \in \mathcal{A}, i \in \mathcal{I}, j \in \mathcal{J},
\end{aligned}
$$

respectively, where the subscript $a$ in variables $c_{2 a}^{i j}, \lambda_{a}^{i j}, \beta_{a}^{i j}$, and $\iota_{a}^{i}$ denotes that these variables are conditional on $a \in \mathcal{A}$ in addition to $i \in \mathcal{I}$ and $j \in \mathcal{J}$.

The planner's optimization with aggregate shocks is identical to the problem described in Allen, Carletti, and Gale (2008). They show that there exists a unique solution to this problem. Intuitively, the first best with aggregate shocks is constructed as follows. The planner stores just enough goods to provide consumption to all impatient agents in the state with many impatient agents, $a=H$. This implicitly defines $c_{1}^{*}$. In this state, patient

\footnotetext{
${ }^{6}$ We refer to $a$ as the "aggregate state variable" (or alternatively as the aggregate-shock state variable) in order to highlight that this state variable corresponds to the amount of the aggregate withdrawal of liquidity from the banking system. While the state variable $i$ does correspond to an aggregate state of the world (crisis or normal-times), we refer to $i$ as the distributional-state variable (or liquidity-shock state variable).
} 
agents consume only goods invested in the long-term technology. In the state with few impatient agents, $a=L$, the planner stores $\left(\bar{\lambda}_{H}-\bar{\lambda}_{L}\right) c_{1}^{*}$ goods in excess of what is needed for impatient agents. These goods are stored between dates 1 and 2 and given to patient agents.

Proposition 5. If $\rho<1$, the central bank can implement the first best allocation.

Proof. We prove this proposition by constructing the allocation the central bank implements. The first-order conditions take the same form as in the case without aggregate risk and become

$$
\begin{aligned}
u^{\prime}\left(c_{1}\right) & =E\left[\frac{\lambda_{a}^{i j}}{\pi \bar{\lambda}_{H}+(1-\pi) \bar{\lambda}_{L}} \iota_{a}^{i} u^{\prime}\left(c_{a 2}^{i j}\right)\right], \quad \text { for } a \in \mathcal{A}, i \in \mathcal{I}, j \in \mathcal{J} \\
E\left[\iota_{a}^{i} u^{\prime}\left(c_{a 2}^{i j}\right)\right] & =r E\left[u^{\prime}\left(c_{a 2}^{i j}\right)\right], \quad \text { for } a \in \mathcal{A}, i \in \mathcal{I}, j \in \mathcal{J} .
\end{aligned}
$$

Assume that the amount of stored goods that the central bank taxes is $\tau_{0}=\left(\bar{\lambda}_{H}-\right.$ $\left.\bar{\lambda}_{L}\right) c_{1}$. Consider the economy with large distributional shocks, $i=1$. If there are many impatient depositors, the banks do not have enough stored goods, on aggregate, for these depositors. However, the central bank can return the taxes at date 1 , setting $\tau_{1 H}=$ $\left(\bar{\lambda}_{H}-\bar{\lambda}_{L}\right) c_{1}$ (and $\left.\tau_{2 H}=0\right)$, so that banks have just enough stored goods on aggregate. The interbank market interest rate is indeterminate, since the supply and demand of stored goods are inelastic, so the central bank can choose the rate to be $\iota^{1}=\frac{c_{2}^{*}}{c_{1}^{*}}$. If there are few impatient depositors, the central bank sets $\tau_{1 L}=0$ (with $\left.\tau_{2 L}=\left(\bar{\lambda}_{H}-\bar{\lambda}_{L}\right) c_{1}\right)$ and $\iota^{1}=\frac{c_{2}^{*}}{c_{1}^{*}}$

Now consider the economy in the case where $i=0$. If there are many impatient depositors, the banks will not have enough stored goods for their them. However, as in the previous case, the central bank can return the taxes at date 1 , setting $\tau_{1 H}=$ $\left(\bar{\lambda}_{H}-\bar{\lambda}_{L}\right) c_{1}\left(\right.$ and $\left.\tau_{2 H}=0\right)$, so that banks have enough stored goods. There is no activity in the interbank market, and the interbank market rate is indeterminate. If there are few 
impatient depositors and the central bank sets $\tau_{1 L}=0$ (with $\left.\tau_{2 L}=\left(\bar{\lambda}_{H}-\bar{\lambda}_{L}\right) c_{1}\right)$, then banks have just enough goods for their impatient depositors at date 1. Again, there is no activity in the interbank market, and the interbank market rate is indeterminate. Hence, the interbank market rate can be chosen to make sure that equation (36) holds.

With interbank market rates set in that way, banks will choose the optimal investment. Indeed, since equation (36) holds, banks are willing to invest in both storage and the longterm technology. In states where there is a zero distributional shock, there is no interbank market lending, so any deviation from the optimal investment carries a cost. In states where there is a positive distributional shock, the rate on the interbank market is such that the expected utility of a bank's depositors cannot be higher than under the first best allocation, so there is no benefit from deviating from the optimal investment in these states.

The interest rate policy of the central bank is effective only if the inelastic parts of the supply and demand curves overlap. With aggregate liquidity shocks, this need not happen, which creates inefficiencies. Proposition 5 illustrates that the role of the liquidity injection policy is to modify the amount of liquid assets in the market so that the interest rate policy can be effective. Hence, the central bank uses different tools to deal with aggregate and distributional shocks. When an aggregate shock occurs, the central bank needs to inject liquidity in the form of stored goods. In contrast, when an distributional shock occurs, the central bank needs to lower interest rates. Both actions are necessary if both shocks occur simultaneously.

During the recent crisis, certain central banks have used tools that have been characterized as similar to fiscal policy. This is consistent with our model in that the central bank policy of taxing and redistributing goods in the case of aggregate shocks resembles fiscal policy. The model does not imply that the central bank should be the preferred 
institution to implement this kind of policy. For example, we could assume that different institutions are in charge of 1) setting the interbank rate, and 2) choosing $\tau_{0}, \tau_{1 a}, \tau_{2 a}$, $a \in A$. Regardless of the choice of institutions, our model suggests that implementing a good allocation may require using tools that resemble fiscal policy in conjunction with more standard central bank tools.

In the U.S., the Federal Reserve has conducted several operations during the crisis that are broader than traditional monetary policy tools to provide aggregate liquidity. Under the Agency Mortgage-Backed Securities (MBS) Purchase Program, the Federal Reserve is purchasing $\$ 1.25$ trillion of agency MBS. The Federal Reserve financed large asset purchases involving Bear Stearns and AIG. The Federal Reserve has extended funding for various securities, markets and institutions beyond the traditional scope of Open Market Operations and the Discount Window through the Commercial Paper Funding Facility $(\mathrm{CPFF})$, the Asset-Backed Commercial Paper Money Market Mutual Fund Liquidity Facility (AMLF), and the Money Market Investor Funding Facility (MMIFF), and the Term Asset-Backed Securities Loan Facility (TALF). The CPFF targeted funding for issuers of commercial paper, while the AMLF and MMIFF targeted funding for money market funds to help against redemption requests, and the TALF provided funding to support the issuance of asset-backed securities targeted towards credit needs for households and small businesses. In these transactions, the Federal Reserve has taken potential interest rate and credit risk, which theoretically could lead to losses that are borne by taxpayers through reduced revenues delivered to the Treasury by the Federal Reserve. 


\section{Contingent interest rate setting and financial sta-}

\section{bility}

Our model allows us to shed light on the role of the interbank market in coping with distributional liquidity shocks and the impact of interest rates on the ex-post redistribution of risks. In our framework, a contingent interest-rate-setting policy dominates a noncontingent one. This is a strong criticism of the conventional view supporting the separation of prudential regulation and monetary policy. We now proceed to compare contingent and noncontingent interest rate policy in terms of financial stability. We show that fundamental bank runs can occur for a noncontingent interest-rate-setting policy, whereas they cannot arise when a contingent interest rate setting is implemented. Thus, contingent interest-rate-setting policy, and the rejection of separation between prudential and monetary policies, fares better also in terms of financial stability.

To simplify the exposition, we assume that the probability of an aggregate liquidity shock is zero, such that the fraction of impatient depositors is always $\bar{\lambda}$, as in the basic distributional-shock model of Section 3. We now consider a wider range of parameters. We no longer require that $c_{2}^{i j}>c_{1}$; we now consider any parameters such that $c_{2}^{i j}>0$. This allows us to consider fundamental bank runs, which we define as occurring to bank $j$ in state $i$ if $c_{2}^{i j}<c_{1}$. In this case, each impatient consumer prefers to withdraw at date 1 even if all other consumers withdraw at date 2. The origin of possible fundamental bank runs is that, in the state where $i=1$, patient depositors of banks with many impatient agents

will consume less if the central bank sets the interest rate higher than $\frac{c_{2}^{*}}{c_{1}^{*}}$. If $\varepsilon$ is large, it may be the case that the consumption of patient depositors of banks with many impatient agents would be lower if they withdraw at date 2 than if they withdraw at date 1 , which would trigger a bank run. Obviously, if the optimal contingent interest-rate-setting policy 
is applied, and $i^{1}=\frac{c_{2}^{*}}{c_{1}^{*}}$, fundamental bank runs are ruled out.

Proposition 6. If $\bar{\lambda} \geq 1 / 2$ and the central bank chooses to implement a noncontingent interest rate policy, for $\rho$ sufficiently low there exist $\varepsilon$ sufficiently large such that bank runs will occur in equilibrium.

Proof. The central bank sets an interest rate $\iota^{1}=\iota^{0}=r>\frac{c_{2}^{*}}{c_{1}^{*}}$. For $\iota^{i}>1, i \in \mathcal{I}$, the first-order conditions of the bank's optimization with respect to $\beta^{i j}$, equations (18) and (19), do not bind, implying $\beta^{i j}=0$ for $i \in \mathcal{I}, j \in \mathcal{J}$. As $\rho$ converges to 0 , by continuity, equilibrium allocations converge to

$$
c_{2}^{1 h}=\frac{\alpha r-\varepsilon c_{1} r}{1-\bar{\lambda}-\varepsilon}=\frac{r}{1-\bar{\lambda}-\varepsilon}\left[\alpha-\varepsilon c_{1}\right]
$$

with $c_{1}=\frac{1-\alpha}{\bar{\lambda}}$ and $c_{2}^{0}=\frac{\alpha r}{1-\bar{\lambda}}$. A fundamental bank run will occur in state $i=1$ if and only if $c_{2}^{1 h}<c_{1}$. This is equivalent to

$$
r\left[\alpha-\varepsilon c_{1}\right]<(1-\bar{\lambda}-\varepsilon) c_{1}
$$

so that $\varepsilon$ has to satisfy

$$
\varepsilon>\frac{r \alpha-(1-\bar{\lambda}) c_{1}}{c_{1}(r-1)}
$$

or equivalently

$$
\varepsilon>\frac{(1-\bar{\lambda})\left(\frac{c_{2}^{0}}{c_{1}}-1\right)}{r-1} .
$$

Recall that $0 \leq \lambda^{i j} \leq 1$ implies $\varepsilon \leq \min \{\bar{\lambda}, 1-\bar{\lambda}\}$. If $\bar{\lambda} \geq \frac{1}{2}$, then this condition becomes $\varepsilon \leq 1-\bar{\lambda}$. The condition on parameters such that $c_{2}^{i j}>0$ requires $\varepsilon<\frac{\alpha}{c_{1}}$, which is sufficient to ensure $\varepsilon \leq 1-\bar{\lambda}$ since $\alpha=1-\bar{\lambda} c_{1}$ and $c_{1}>1$. So, bank runs 
will occur for $\varepsilon \in\left(\frac{(1-\bar{\lambda})\left(\frac{c_{2}^{0}}{c_{1}}-1\right)}{r-1}, \frac{\alpha}{c_{1}}\right)$, which is a non-empty interval. Thus, there exist $\varepsilon$ for which bank runs will occur. Now, since bank runs are anticipated, banks could choose a "run preventing" deposit contract, as suggested by Cooper and Ross (1998). However, following the argument in that paper, banks will not choose a run-preventing deposit contract if the probability of a bank run is sufficiently small. So for $\rho$ sufficiently close to zero, there exist $\varepsilon$ for which bank runs will occur in equilibrium.

\section{Liquidation of the long-term technology}

We endogenize the amount of liquid assets available in the interbank market at date 1 by extending the model to allow for premature liquidation of the investment. Allowing for liquidation also allows us to examine the robustness of the central bank's interest rate policy to banks' options outside of borrowing on the interbank market. Banks in need of liquidity may choose to liquidate investment if the interbank rate is too high. This can restrict the set of feasible real interbank rates and may preclude the first best equilibrium. Indeed, as banks have the alternative option of liquidating their assets, interbank market rates that are larger than the return on liquidation are not feasible, and this might restrict the central bank's policy options.

Again, to simplify the exposition, we assume that the fraction of impatient depositors is always $\bar{\lambda}$. At date 1 , bank $j$ can liquidate $\gamma^{i j}$ of the investment for a salvage rate of return $s$ at date 1 and no further return at date 2. The bank budget constraints (3) and (4) are replaced by

$$
\begin{aligned}
\lambda^{i j} c_{1} & =1-\alpha-\beta^{i j}+\gamma^{i j} s+f^{i j} \quad \text { for } i \in \mathcal{I}, j \in \mathcal{J} \\
\left(1-\lambda^{i j}\right) c_{2}^{i j} & =\left(\alpha-\gamma^{i j}\right) r+\beta^{i j}-f^{i j} \iota^{i} \quad \text { for } i \in \mathcal{I}, j \in \mathcal{J},
\end{aligned}
$$


respectively, and the bank optimization (7) is replaced by

$$
\begin{array}{rl}
\max _{\alpha, c_{1},\left\{\beta^{i j}, \gamma^{i j}\right\}_{i \in \mathcal{I}, j \in \mathcal{J}}} & E[U] \\
\text { s.t. } & \beta^{i j} \leq 1-\alpha \quad \text { for } i \in \mathcal{I}, j \in \mathcal{J} \\
& \gamma^{i j} \leq \alpha \quad \text { for } i \in \mathcal{I}, j \in \mathcal{J} \\
& \text { equations (37) and (38). }
\end{array}
$$

The ability for banks to liquidate long-term assets for liquid assets and lend them on the interbank market restricts the ex-post equilibrium interest rate from being too high. This is the case because, for any state $i$, the ex-post equilibrium rate is restricted by $\iota^{i} \leq \frac{r}{s}$. Indeed, for $\iota^{i}>\frac{r}{s}$ banks would prefer to liquidate all investment and no banks would borrow. Consequently, the optimal equilibrium cannot be supported if the rate required to support the first best ex-ante equilibrium in state $i=0$ is too high. Proposition 7 gives a more precise statement:

Proposition 7. If $\iota^{0 *}=r+\frac{\rho\left(r-\frac{c_{2}^{*}}{c_{1}^{*}}\right)}{1-\rho}>\frac{r}{s}$, the first best cannot be achieved as a contingent interest-rate-setting market equilibrium.

Proof. If $\iota^{0 *}>\frac{r}{s}$, then the equilibrium rate is $\iota^{0}<\frac{r}{s}<\iota^{0 *}$; it is less than the equilibrium rate required to support a first best equilibrium.

If the probability of a crisis is low enough, then the first best equilibrium is always feasible. The limit of $\iota^{0 *}$ as $\rho \longrightarrow 0$ is $r$. Moreover, for small $\rho, \iota^{0 *}$ has to be only slightly greater than $r$ for the interest rate in expectation to equal $r$, because the probability of the rate being low during a crisis is small. This result is expressed in the next proposition.

Proposition 8. For any $s \leq 1$, there exists a $\widehat{\rho}>0$ such that for all $\rho \in(0, \widehat{\rho}), \iota^{0 *}<\frac{r}{s}$ and the first best ex-ante equilibrium exists. 
Proof. Consider $\widehat{s}<1$ and define $\widehat{\rho} \equiv \frac{r(1-\widehat{s})}{1+\widehat{s}\left(r-\frac{c_{2}^{*}}{c_{1}^{*}}\right)}>0$. The first best equilibrium exists if

$$
\begin{aligned}
\iota^{0 *} & <\frac{r}{s} \\
& \Longleftrightarrow r+\frac{\rho\left(r-\frac{c_{2}^{*}}{c_{1} *}\right)}{1-\rho}<\frac{r}{s} \\
& \Longleftrightarrow \rho<\widehat{\rho} .
\end{aligned}
$$

It is interesting to emphasize that, as $s$ stands for salvage value of the investment, it can be interpreted as the liquidity of a market for the long-run technology. From that perspective, our result states that the higher the liquidity of the market for the long-term technology, the lower the ex-ante efficiency of the banking system. Our result is surprising in the context of central bank policy, but it is quite natural in the context of DiamondDybvig models, where the trading of deposits destroys the liquidity insurance function of banks.

\section{Conclusion}

The Federal Reserve drastically lowered the fed funds rate during the recent banking crisis. The insights of our model explain the benefits of low rates for the efficient redistribution of liquidity in the interbank market.

Our paper provides micro-foundations for the interbank market role in allocating liquidity, which is important in order to understand how central banks should respond to liquidity shocks. Two types of liquidity shocks are considered: distributional shocks and aggregate shocks. The main insight is that, because of the inelasticity of the short-term market for the liquid asset, the central bank can pick an optimal equilibrium from a set of equilibria by setting the interest rate in the interbank market appropriately. Faced with

a distributional shock, the central bank should lower the interbank rate to facilitate the 
reallocation of liquid assets between banks in the interbank market. However, in order to provide incentives for banks to hold enough liquid assets ex ante, the central bank must make sure that interbank rates are high enough when the distributional shock does not occur.

On the other hand, the central bank should respond to aggregate shocks with a policy of injecting liquid assets in the economy. The goal of this policy is twofold. First, it helps achieve the optimal distribution of consumption between patient and impatient depositors. Second, it sets the amount of liquid assets in the interbank market at the level at which the central bank can adjust the interbank rate to address the suboptimal distribution of liquidity among banks. Hence, the liquidity injection policy required in the face of aggregate shocks complements the interest rate policy that is optimal in the face of distributional shocks.

Our model also shows that a failure to implement the optimal interest rate policy can lead to bank runs. When the interbank market rate is not set appropriately, a distributional shock creates consumption risk for patient depositors. If the rate is high, banks that need to borrow in the interbank market will be left with few goods for their patient depositors. For some parameter values, and if the rate is high enough, the goods available to patient depositors will yield less consumption than the amount promised to impatient depositors. This will create a run as all patient depositors will have an incentive to claim to be impatient. Even without considering risky long-term assets and counterparty risk, we show how liquidity shocks can create banking fragility under suboptimal interest rate policy. Our model provides an important framework for future research that incorporates credit risk with liquidity risk to examine the impact of central bank rate policy on longer term interbank interest rates. 


\section{Appendix: Generalization to $\mathrm{N}$ states}

Consider a generalization of the baseline model (without runs or liquidation of long-term assets) with $N$ distributional-shock states $i_{1}, \ldots, i_{N} \geq 0$. We assume $i_{1}=0, \lambda^{i_{n} H}=\bar{\lambda}+i_{n} \varepsilon$, and $\lambda^{i_{n} L}=\bar{\lambda}-i_{n} \varepsilon$, where $i_{n} \in\left\{i_{1}, \ldots, i_{N}\right\}$. The probability of $i_{n}$ is $\rho_{n}, \sum_{n=1}^{N} \rho_{n}=1$.

A bank's problem is thus

$$
\begin{aligned}
\max _{\alpha \in[0,1] ; c_{1},\left\{\beta^{i j}\right\}_{i \in \mathcal{I}, j \in \mathcal{J} \geq 0}} & \bar{\lambda} u\left(c_{1}\right)+\sum_{n=1}^{N} \rho_{n}\left[\frac{1}{2}\left(1-\lambda^{i_{n} H}\right) u\left(c_{2}^{i_{n} H}\right)+\frac{1}{2}\left(1-\lambda^{i_{n} L}\right) u\left(c_{2}^{i_{n} L}\right)\right] \\
\text { s.t. } & \lambda^{i_{n} j} c_{1} \leq 1-\alpha+\beta^{i_{n} j}+f^{i_{n} j} \\
& \left(1-\lambda^{i_{n} j}\right) c_{2}^{i_{n} j} \leq \alpha r-\beta^{i_{n} j}-f^{i_{n} j} \iota^{i_{n}} \\
& \text { for } i_{n} \in\left\{i_{1}, \ldots, i_{N}\right\}, j \in \mathcal{J} .
\end{aligned}
$$

The first-order conditions with respect to $\alpha$ and $c_{1}$ are, respectively,

$$
\begin{aligned}
& \sum_{n=1}^{N} \rho_{n}\left[\frac{1}{2} u^{\prime}\left(c_{2}^{i_{n} H}\right)+\frac{1}{2} u^{\prime}\left(c_{2}^{i_{n} L}\right)\right] \iota^{i_{n}}=\sum_{n=1}^{N} \rho_{n}\left[\frac{1}{2} u^{\prime}\left(c_{2}^{i_{n} H}\right)+\frac{1}{2} u^{\prime}\left(c_{2}^{i_{n} L}\right)\right] r \\
& u^{\prime}\left(c_{1}\right)=\sum_{n=1}^{N} \rho_{n}\left[\frac{\lambda^{i_{n} H}}{2 \bar{\lambda}} u^{\prime}\left(c_{2}^{i_{n} H}\right)+\frac{\lambda^{i_{n} L}}{2 \bar{\lambda}} u^{\prime}\left(c_{2}^{i_{n} L}\right)\right] \iota^{i_{n}} .
\end{aligned}
$$

By the same logic as in the case with two states, the interest rate in the interbank market should be equal to $\frac{c_{2}^{*}}{c_{1}^{*}}$ whenever $i_{n}>0$ in order to facilitate risk sharing between banks. Without loss of generality, assume that $i_{n}>0$ for all $n \geq 2$. Then we have $\iota^{i_{n}}=\frac{c_{2}^{*}}{c_{1}^{*}}$ and $c_{2}^{i_{n} H}=c_{2}^{i_{n} L}=\frac{\alpha r}{1-\bar{\lambda}}$ for all $n \geq 2$. Let $\rho=\sum_{n=2}^{N} i_{n}$, and then we can write interest rate $\iota^{i_{1}}$ as

$$
\iota^{i_{1}}=r+\frac{\rho\left(r-\frac{c_{2}^{*}}{c_{1}^{*}}\right)}{1-\rho},
$$

which is equal to $\iota^{0}=\iota^{0^{*}}$ in the two-state baseline model. ${ }^{7}$

\footnotetext{
${ }^{7}$ We can show that if there is no state with a zero-size shock, then a first best equilibrium does not exist because an equilibrium requires an interest rate of $l^{i}>\frac{c_{2}^{*}}{c_{1}^{*}}$ for at least one distributional-shock state $i$,
} 


\section{References}

[1] Acharya, Viral V. and Tanju Yorulmazer (2008). "Cash-in-the-Market Pricing and Optimal Resolution of Bank Failures," Review of Financial Studies 21(6), 2705-2742.

[2] Allen, Franklin, Elena Carletti and Douglas Gale (2008). "Interbank Market Liquidity and Central Bank Intervention," working paper.

[3] Allen, Franklin and Douglas Gale (2004). "Financial Fragility, Liquidity, and Asset Prices," Journal of the European Economic Association 2, 1015-1048.

[4] Ashcraft, Adam, James McAndrews and David Skeie (2008). "Precautionary Reserves and the Interbank Market," Federal Reserve Bank of New York Staff Reports no. 370 .

[5] Bagehot, Walter (1873). Lombard Street: A Description of the Money Market. (Scriber, Armstrong, and Co., New York).

[6] Bhattacharya, Sudipto and Douglas Gale (1987). "Preference Shocks, Liquidity and Central Bank Policy," in W. Barnett and K. Singleton (eds.), New Approaches to Monetary Economics, Cambridge University Press, 69-88.

[7] Bolton, Patrick, Tano Santos and Jose Scheinkman (2008). "Inside and Outside Liquidity," working paper.

[8] Cooper, R. and T. W. Ross (1998). "Bank Runs: Liquidity Costs and Investments Distortions," Journal of Monetary Economics 41, 27-38.

which is then always distortionary. If the baseline model is modified with two distributional-shock states $0<i_{0}<i_{1}$, we can show that there is a constrained-efficient equilbrium with $l^{1^{*}}<l^{i_{1}}<r<l^{i_{0}}<l^{0^{*}}$ which is chosen by the central bank. 
[9] Diamond, Douglas W. and Phillip H. Dybvig (1983). "Bank Runs, Deposit Insurance, and Liquidity," Journal of Political Economy 91, 401-419.

[10] Diamond, Douglas W. and Raghuram G. Rajan (2008). "Illiquidity and Interest Rate Policy," working paper.

[11] Di Giorgio, Giorgio and Carmine Di Noia (1999). "Should Banking Supervision and Monetary Policy Tasks Be Given to Different Agencies?" International Finance 2, $361-378$.

[12] Freixas, Xavier and Cornelia Holthausen (2005). "Interbank Market Integration under Asymmetric Information," Review of Financial Studies 18, 459-490.

[13] Freixas, Xavier and Jose Jorge (2008). "The Role of Interbank Markets in Monetary Policy: A Model with Rationing," Journal of Money, Credit and Banking 40(6), 1151-1176.

[14] Freixas, Xavier, Antoine Martin and David Skeie (2009). "Bank Liquidity, Interbank Markets, and Monetary Policy," Federal Reserve Bank of New York Staff Reports no. 371 .

[15] Goodfriend, Marvin (2002). "Interest on Reserves and Monetary Policy," Federal Reserve Bank of New York Economic Policy Review 8, 77-84.

[16] Goodfriend, Marvin and Robert G. King (1988). "Financial Deregulation, Monetary Policy, and Central Banking," Federal Reserve Bank of Richmond Economic Review May/June, 3-22.

[17] Goodhart C. and D. Shoenmaker (1995). "Should the Functions of Monetary Policy and Banking Supervision Be Separated?" Oxford Economic Papers, 539-560. 
[18] Gorton, Gary and Lixin Huang (2006). "Bank Panics and the Endogeneity of Central Banking," Journal of Monetary Economics 53(7), 1613-29.

[19] Guthrie, Graeme and Julian Wright (2000). "Open Mouth Operation," Journal of Monetary Economics 46, 489-516.

[20] Heider, Florian, Marie Hoerova and Cornelia Holthausen (2008). "Information Asymmetries in the Interbank Market: Theory and Policy Responses," working paper.

[21] Ioannidou, Vasso P. (2005). "Does Monetary Policy Affect the Central Bank's Role in Bank Supervision?" Journal of Financial Intermediation 14, 58-85.

[22] Martin, Antoine (2006). "Liquidity Provision vs. Deposit Insurance: Preventing Bank Panics without Moral Hazard," Economic Theory 28, 197-211.

[23] Martin, Antoine (2009). "Reconciling Bagehot and the Fed's Response to September 11," Journal of Money, Credit, and Banking 41, 397-415.

[24] Skeie, David R. (2008). "Banking with Nominal Deposits and Inside Money," Journal of Financial Intermediation 17, 562-584.

[25] Whitesell, William (2006). "Interest Rate Corridors and Reserves," Journal of Monetary Economics 53, 1177-1195. 